\title{
Relationships between species feeding traits and environmental conditions in fish communities: a three-matrix approach
}

\author{
Anik Brind'amour ${ }^{1,3,{ }^{*}}$ Daniel Boisclair ${ }^{1}$ Stéphane Dray $^{2}$ \\ and Pierre Legendre ${ }^{1}$ \\ ${ }^{1}$ Département de Sciences Biologiques, Université de Montréal, C.P. 6128, Succursale Centre-ville, \\ Montréal, Québec H3C3J7 Canada \\ ${ }^{2}$ Université de Lyon, F-69000, Lyon, France, and Université Lyon 1, CNRS, UMR 5558, Laboratoire \\ de Biométrie et Biologie Evolutive, 43 Boulevard du 11 Novembre 1918, F-69622 Villeurbanne, France \\ ${ }^{3}$ Present address: Ifremer, Centre de Nantes, Rue de l'lle d'Yeu, B.P. 21105, F-44311 Nantes, France \\ *Corresponding author : Anik Brind'amour, email address: Anik.Brindamour@ifremer.fr
}

\begin{abstract}
:
Understanding the relationships between species biological traits and the environment is crucial to predicting the effect of habitat perturbations on fish communities. It is also an essential step in the assessment of the functional diversity. Using two complementary three-matrix approaches (fourthcorner and RLQ analyses), we tested the hypothesis that feeding-oriented traits determine the spatial distributions of littoral fish species by assessing the relationship between fish spatial distributions, fish species traits, and habitat characteristics in two Laurentian Shield lakes. Significant associations between the feeding-oriented traits and the environmental characteristics suggested that fish communities in small lakes (displaying low species richness) can be spatially structured. Three groups of traits, mainly categorized by the species spatial and temporal feeding activity, were identified. The water column may be divided in two sections, each of them corresponding to a group of traits related to the vertical distribution of the prey coupled with the position of the mouth. Lake areas of low structural complexity were inhabited by functional assemblages dominated by surface feeders while structurally more complex areas were occupied by mid-water and benthic feeders. A third group referring to the time of feeding activity was observed. Our work could serve as a guideline study to evaluate species traits3environment associations at multiple spatial scales. Our results indicate that three-matrix statistical approaches are powerful tools that can be used to study such relationships. These recent statistical approaches open up new research directions such as the study of spatially based biological functions in lakes. They also provide new analytical tools for determining, for example, the potential size of freshwater protected areas.
\end{abstract}

Key words: ecological niche; feeding traits; fish communities; fourth-corner method; functional group; habitat; lake; Laurentian Shield lakes, Quebec, Canada; littoral zone; spatial scale; three-matrix approach 


\section{INTRODUCTION}

Assessing the habitat characteristics required by fish to complete their life cycles is of primary importance to predict the effect of habitat perturbations or losses on fish communities and identify the environmental conditions that should be protected for conservation purposes. Differences in the species composition of fish communities among systems and variations in the

6 response of fish species to environmental conditions are major obstacles to the development of

7 habitat models that may be applied to many fish species in many ecosystems (Olden and Jackson

8 2002). Functional classification of fish species in which fish that share common traits are grouped

9 together represents an alternative to individual species-environment models and may circumvent

10 these obstacles (McGill et al. 2006). According to Austen et al. (1994), groups of traits form

11 operational units that respond to environmental changes in a more predictable way than

12 individual species, thereby improving the predictive capabilities of habitat models in comparison

13 to models developed at high levels of taxonomic resolution (i.e., species level). Grouping species

14 according to traits is also a way of identifying functional groups of species to assess "key"

15 functions of an ecosystem: this is an essential step in assessing functional diversity within and 16 between ecosystems (Mouillot et al. 2006, Brind'Amour et al. 2009).

17 Habitats have long been argued to act as templates on which evolution forges phenotypic

18 attributes (Southwood 1977, 1988). Habitat characteristics can be viewed as filters imposed on 19 species gene pools to select traits suited to a particular set of environmental conditions (Díaz et

20 al. 1998). These concepts notably refer to the "niche filtering hypothesis" and suggest that 21 species sharing similar traits form functional groups that may likely occupy similar habitats

22 (Tonn et al. 1990, Zobel 1997). Grouping species according to traits, such as morphology or

23 behavior, is one way to simplify species-rich communities and thus increase the transferability of 24 habitat models among ecosystems (Angermeier and Winston 1998). For instance, traits referring 
1 to the beta niche of species (i.e. the type of resources used by species or their mode of

2 acquisition, Ackerly and Cornwell 2007) have been used recently to describe the ecological

3 processes generating species interactions along an altitudinal gradient (Mason et al. 2007).

4 Conclusions from Mason et al. (2007) as well as from early studies (Keast and Webb 1966)

5 suggest that feeding-oriented traits may represent good descriptors of fish communities, and can

6 be used to classify species into functional categories.

The relationship between species traits and the environment is commonly assessed

8 indirectly using a two-step analysis. Fish abundances are first linked to environmental conditions

9 and species responses to environmental variation are then related to the biological and/or

10 physiological traits of species. In such analyses, the relationship between the environment and the

11 species traits is thus assessed indirectly (Thuiller et al. 2004, Santoul et al. 2005). Certain authors

12 accept to sacrifice some information at the species level and compute a traits-sites matrix

13 weighed (or not) by the abundances, which they link directly to the environment (Richards et al.

14 1996, Poff 1997). Although the latter approach may be called a direct functional analysis, the loss

15 of information may be penalizing (Dray and Legendre 2008). Direct assessment of the trait-

16 environment relationships, which keeps all the available ecological information, is rarely done

17 because it requires a statistical method that takes into account simultaneously the information

18 stored in three tables to link fish traits and environmental conditions through fish responses.

19 Among the three-matrix approaches allowing such analyses to be carried out, the RLQ analysis

20 and the fourth-corner method are two complementary approaches. RLQ analysis (Dolédec et al.

21 1996) produces ordination results that can be used to identify the group members of species,

22 species traits, and environmental variables, thereby providing a valuable and complementary tool

23 to the fourth-corner method for the interpretation of the traits-environment relationships. The

24 fourth-corner method was first developed by Legendre et al. (1997) to statistically test the 
1 significance of the correlations between species traits and environmental conditions using a

2 matrix of species traits, a matrix of presence-absence of the species obtained by sampling a series

3 of sites, and a matrix of environmental conditions observed at the sites. Dray and Legendre

4 (2008) have recently revised this method to develop new testing procedures and allow the analysis of the species abundances (instead of presence-absence only) observed at the sampling

6 sites. The modified version of the fourth-corner method is particularly appealing in ecosystems in

7 which generalist species may be present in nearly all sampling sites and for which emerging

8 patterns may only be observable with species abundance data. On the other hand, being recently

9 published, this revised version has been used in very few studies (Tall et al. 2006) and its

10 usefulness still needs to be assess.

11 Our study is addressing the issue of understanding species and trait relations to habitat 12 using the two complementary three-matrix approaches cited above. Since feeding is considered 13 one of the major processes structuring lacustrine fish communities (Gatz 1979a, Pierce et al.

14 1994, Norton 1995, Piet 1998, Mason et al. 2007), we focused mainly on feeding-oriented traits.

15 The objective was to assess whether feeding-oriented traits determine the multiscale distributions

16 of littoral fish species in lakes. It was tested using two lakes from the same watershed, sharing

17 similar geological and biological characteristics. More specifically we (i) define functional

18 groups of species based on feeding-oriented traits, (ii) assess the relationships between the

19 feeding-oriented traits and the environmental conditions, and (iii) investigate the scale-

20 dependency of the feeding-oriented traits and environment correlations.

21 The latter objective (i.e. scale-dependency) was inspired from recent findings on the

22 effect of scale and habitat patchiness on the structure of fish assemblages in lakes (Poizat and

23 Pont 1996, Johnson et al. 2004, Brind'Amour et al. 2005, Stoffels et al. 2005, Brind'Amour and

24 Boisclair 2006). These studies showed that the nature and strength of the relationships between 
1 the species abundances and the environmental variables may vary with the scale at which the

2 analysis is conducted. Scale-dependent functional relationships have been extensively

3 investigated in lotic ecosystems (Poff 1997, Angermeier and Winston 1998, Lamouroux et al.

4 2002, Goldstein and Meador 2004, Higgins 2009) but the concept remains poorly studied in

5 lacustrine ecosystems at the scale of a whole lake (Irz et al. 2007, Eros et al. 2009). This is

6 perhaps because of the river continuum concept (Vannote et al. 1980) and its derived theoretical

7 frameworks (e.g. "landscape filter framework"; Poff 1997), which offers a predictive spatial

8 support to study the structure and functional relationships of fish species in lotic systems. For

9 instance, Goldstein and Meador (2004) developed functional hypotheses using the "landscape

10 filter framework" to predict the relationships between categories of species traits and the size of

11 streams. In lakes, the concept of "hierarchical filters" has been introduced by Tonn et al. (1990).

12 It is a framework similar to the one suggested by Poff (1997), in which fish communities are

13 "environmentally filtered" as we move from the continental-scale to the lake-scale.

14 Unfortunately, that framework cannot be used in the present study to develop functional

15 hypotheses because the filters are not assessed at the same spatial scales than the ones in our 16 study: we are positioned under the finest scale studied by Tonn et al. (1990) and other recent 17 papers (Irz et al. 2007, Eros et al. 2009).

21 lakes are located in the same watershed on the Laurentian Shield in the province of Québec,

22 Canada (Fig. 1). Lake Drouin $\left(46^{\circ} 09^{\prime} \mathrm{N}, 73^{\circ} 55^{\prime} \mathrm{W}\right)$ has a surface area of 31 ha, a maximum depth

23 of $22 \mathrm{~m}$, and a perimeter of $4.8 \mathrm{~km}$ (calculation based on the sum of the linear lengths of our 
1 sampling units). Lake Paré $\left(46^{\circ} 08^{\prime} \mathrm{N}, 73^{\circ} 54^{\prime} \mathrm{W}\right)$ has a surface area of 23 ha, a maximum depth of

$29 \mathrm{~m}$, and a perimeter of $3.1 \mathrm{~km}$. Both lakes present a littoral zone with woody debris, rocky

3 substrate, sandy beaches, and patches of macrophytes of mixed species such as Brasenia

4 schreberi Gmelin, Eriocaulon aquaticum (Hill) Druce, Myriophyllum spicatum L., and

$5 \quad$ Nymphaea odorata Aiton. The two lakes are mesotrophic with similar limnological and

6 geomorphological characteristics. During the period of thermal stratification (May to October),

7 surface water temperatures ranged from $15^{\circ} \mathrm{C}$ to $26^{\circ} \mathrm{C}$ and bottom temperatures from $4^{\circ} \mathrm{C}$ to $8^{\circ} \mathrm{C}$.

8 The thermoclines formed at $4.5 \mathrm{~m}$ depth in mid-June and broke down in early October

9 (Brind'Amour, unpublished data).

The fish community and the environmental variables were quantified at 90 (Lake Drouin)

12 and 60 sites (Lake Paré) that covered the complete perimeter of the littoral zones of the lakes.

13 The sampling sites were defined as an area that possessed fairly homogenous attributes with

14 respect to a combination of environmental variables (i.e., substrate, macrophyte density). Mid-

15 water buoys delimiting the beginning and the end of each site were anchored. The surface area of

16 individual sampling sites ranged from 162.4 to $268.8 \mathrm{~m}^{2}$ (average size $215.6 \mathrm{~m}^{2}$ ) in Lake Drouin

17 and from 109.2 to $390.8 \mathrm{~m}^{2}$ (average size $207.6 \mathrm{~m}^{2}$ ) in Lake Paré. The width of a sampling site (5

18 to $10 \mathrm{~m}$ ) was determined as the distance from the shore to the $3-\mathrm{m}$ depth isobath. The limit of $3 \mathrm{~m}$

19 was adopted because it corresponded to the depth at which all fish observed could be correctly

20 counted and identified to species while snorkeling. The mean width of a site was $10.5 \mathrm{~m}$ (range: 9

21 to $12 \mathrm{~m}$ ) for the two lakes. Geographical coordinates were determined at each site using a global

22 positioning system (Garmin - GPS 12) with a precision of $\pm 10 \mathrm{~m}$. 
Fish community. - The sites from both lakes were surveyed three times (i.e., on three

2 consecutive days between 09:00 and 15:00) between 25 July and 4 August 2001. The data for the

3 three days were then averaged within homologous sites of the lake. This procedure was done to

4 minimize the effects of daily variations of fish community characteristics at each site. The

5 detailed justification for this procedure is given in Web Appendix 1 of Brind'Amour et al. (2005).

6 Survey of the fish community was done using a modified version of the visual survey technique

7 described by Harmelin-Vivien et al. (1985). The technique and its sampling efficiency are fully

8 detailed in Brind'Amour and Boisclair (2004). It requires two observers who snorkel at the water

9 surface performing zigzags over the complete length and width of a sampling site following a

10 trajectory that is parallel to shore. During such sampling, the distance between the two observers

11 was $4 \mathrm{~m}$. The observers covered nearly $90 \%$ of the total area of each sampling site. They

12 maintained a constant swimming speed of $10 \mathrm{~m} \mathrm{~min}^{-1}$ to minimize fish disturbance (Eklöv 1997).

13 Data were recorded on polyvinyl chloride (PVC) cylinders that snorkellers wore around their

14 forearm. Snorkellers identified the species, the relative abundance and the approximate size (i.e.

15 small, medium, large) of the fish observed as they progressed along their respective transect.

16 Preliminary identification of fish species and relative size had been conducted prior to the study

17 in order to normalize the sampling protocol.

18 We recorded a total of nine species in the two lakes (Table 2): 8 in Lake Drouin and 6 in

19 Lake Paré. Pumpkinseed (Lepomis gibbosus) represented 51\% of the fish surveyed, whereas

20 seven species represented each less than $20 \%$ of the observations: golden shiner (Notemigonus

21 crysoleucas), creek chub (Semotilus atromaculatus), banded killifish (Fundulus diaphanus),

22 brown bullhead (Ameiurus nebulosus), yellow perch (Perca flavescens), lake chub (Couesius

23 plumbeus), and white sucker (Catostomus commersoni). The fathead minnow (Pimephales

24 promelas), which accounted for less than $0.5 \%$ of the observations, was excluded from the 
1 analyses. This was done because it was impossible to assess if the low abundance observed for $P$.

2 promelas was due its rarity or to methodological limits.

Environmental variables. - The sampling sites were characterized by ten environmental variables (Table 1). All environmental variables, with the exceptions of density of macrophytes and fetch, were surveyed at the end of May 2001. The density of macrophytes was estimated on

6 July 29 in Lake Drouin and July 27 in Lake Paré. The density of macrophytes at each site was

7 estimated by two snorkelers using four randomly selected quadrats of $1 \mathrm{~m}^{2}$ (a $1 \mathrm{~m}^{2}$ frame was

8 thrown from the centre of the sampling site in different directions within each site). The number

9 of stems of emergent and submersed species was counted in the $1-\mathrm{m}^{2}$ frame. The average number

10 of stems from the four replicates was used in the statistical analyses. The percentage of cover,

11 mainly composed of a dense decaying weed bed of $M$. spicatum and/or unidentified species, was

12 estimated and used as the 'bottom cover' variable. Fetch was calculated on each sampling day as

13 the distance to the shore in the direction of the dominant wind.

14 Environmental Complexity Index (ECI). - We developed an index to estimate the

15 environmental complexity of the littoral zone of the studied lakes. That index, which we called

16 the Environmental Complexity Index (ECI), sums the squared pairwise dissimilarities (Gower

17 distances) between the sites of each lake that we then divide by the number of sites to make the

18 indices comparable. ECI measures the total environmental variation captured in the Gower

19 dissimilarity matrix. Greater variability in the matrix of sites-by-environmental characteristics

20 leads to greater dissimilarity among the sites and, thereby, to greater ECI. Details concerning the

21 computation of that index are found in Appendix B. 
Analytical framework

We tested the hypothesis that morphological and behavioral traits determine the spatial

3 distributions of the littoral fish species in the two lakes, using the fourth-corner method

4 (Legendre et al. 1997). This approach requires multiple data taking the form of three input matrices $(\mathbf{R}, \mathbf{L}$ and $\mathbf{Q})$ and computes species trait-environment correlations in a fourth matrix (D;

6 Fig. 2). This section presents the information contained in each matrix used in fourth-corner analysis and describes the field methods used to collect that information.

Matrix L: Abundance of the fish species. - The first matrix $(\mathbf{L}: m \times k)$ contained the

9 abundances of the $k$ species at the $m$ sampling sites. It was composed of 7 species at 90 sampling

10 sites in Lake Drouin, and 6 species at 60 sampling sites in Lake Paré. The abundance data were

11 transformed using square root to reduce the influence of the dominant species in the analysis of

12 community structure (Sokal and Rohlf 1995). Matrix Q: Morphological and behavioral traits. — The second matrix $(\mathbf{Q}: k \times n)$

14 described $n$ morphological or behavioral traits of the same $k$ species. Data (i.e. the 8 traits) in this 15 matrix were obtained from several studies providing information on the fish species present in the 16 two lakes (Scott and Crossman 1973, Becker 1983, Carlander 1997, Ultsch et al. 1999, Robb and 17 Abrahams 2002). The species were described using eight feeding-oriented and behavioral traits 18 (Table 3) that had been found to be significantly associated with the environmental conditions in 19 other studies. Some of the traits were not mutually exclusive; a species could be coded as feeding 20 on several types of prey and in different parts of the water column (water surface, mid-water, or 21 bottom). Matrix R: Environmental variables. — The third matrix $\mathbf{R}(m \times p)$ displayed information 23 about the $p$ environmental variables at the $m$ sampling sites. As our third objective was to 
1 investigate the scale-dependency of the feeding-oriented traits and environment correlations, we

2 assessed the link between the species traits and the environmental variables over multiple spatial

3 scales by modeling spatially the environmental variables at four spatial scales (see next paragraph

4 for details). Therefore, we created four matrices $\mathbf{R}_{\mathrm{VB}}, \mathbf{R}_{\mathrm{B}}, \mathbf{R}_{\mathrm{M}}$ and $\mathbf{R}_{\mathrm{F}}(m \times p)$, one for each spatial

5 scale, containing the spatially-modeled environmental variables.

The spatial modeling of the environmental variables was done using Principal

7 Coordinates of Neighbor Matrices (PCNM) (Borcard and Legendre 2002, Borcard et al. 2004).

8 PCNM eigenvectors represent a spectral decomposition of the spatial relationships among the

9 sampling sites and describe all spatial scales that can be accommodated in the sampling design

10 (Dray et al. 2006). They were obtained by principal coordinate analysis (PCoA) of a truncated

11 geographic distance matrix among the sites, as explained in the above-mentioned papers (step 1

12 in Fig. 2). In the present study, all distances larger than the distance between the centers of

13 adjacent sites were replaced by 4 times that value, before PCoA. The resulting principal

14 coordinates, which are called PCNM variables or eigenvectors, were then used as spatial

15 predictors to analyze the spatial variation of the environmental variables. The PCNM variables

16 corresponded to a series of vectors maximizing the spatial autocorrelation measured by Moran's $I$

17 and constitute a model of spatial structures at multiple scales (Dray et al. 2006). Only the PCNM

18 eigenvectors modeling positive spatial correlation, as verified by the computation of Moran's I

19 statistics, were included in the next step of variable selection in a multiple regression analysis. A

20 forward selection was then done to identify the significant PCNMs (26 for Lake Drouin and 21

21 for Lake Paré) explaining the environmental variability (step 2 in Fig. 2). The significant PCNMs

22 were divided into four groups corresponding to as many spatial scales: very broad, broad, meso,

23 and fine; see Brind'Amour et al. (2005) for details. We described the spatial scales as patches or 
1 sections corresponding to a percentage of the lake perimeter. For instance, the very broad scale

2 corresponded to patches of nearly $40 \%$ of the total perimeter of each lake, i.e. $1900 \mathrm{~m}$ and 1200

$3 \mathrm{~m}$ for Lakes Drouin and Paré respectively; the broad scale to sections of 10 to $20 \%$ of the total

4 perimeter; the meso scale to sections of 5 to $10 \%$ of the total perimeter; and the fine scale to

5 sections smaller than $5 \%$ of the total perimeter. Associations between the environmental variables

6 and the groups of PCNMs at the four spatial scales were computed using either multiple

7 regressions for the quantitative continuous variables, or logistic regressions for the binary

8 variables (step 3 in Fig. 2). The predicted values (for the quantitative variables) or the

9 probabilities (for the binary variables) at the sampling sites, which represented the relevant

10 information, were used to form four matrices $\mathbf{R}_{\mathrm{VB}}, \mathbf{R}_{\mathrm{B}}, \mathbf{R}_{\mathrm{M}}$ and $\mathbf{R}_{\mathrm{F}}$. Therefore, these matrices

11 were composed of the environmental conditions predicted at each spatial scale, thereby

12 corresponding to the spatially-modeled environmental conditions. The multiple and logistic

13 regressions were computed using the free software R 2.6.1 (R Development Core Team, 2005). Species traits-environment relationships (step 4 in Fig. 2). — Matrix $\mathbf{D}(n \times p)$ contained

15 the results obtained after conducting the fourth-corner analysis. It was composed of correlations

16 of the $n$ morphological or behavioral traits (matrix $\mathbf{Q}$ ) crossed with the $p$ environmental variables

17 (matrix R). For each lake, we conducted the analysis four times, one for each spatial scale (i.e.,

18 using the four different $\mathbf{R}_{\mathrm{VB}}, \mathbf{R}_{\mathrm{B}}, \mathbf{R}_{\mathrm{M}}$ and $\mathbf{R}_{\mathrm{F}}$ matrices) leading to four matrices $\mathbf{D}_{\mathrm{VB}}, \mathbf{D}_{\mathrm{B}}, \mathbf{D}_{\mathrm{M}}$ and

$19 \mathbf{D}_{\mathrm{F}}$. The analyses were performed using the function 'fourthcorner' of the ade4 package (Dray

20 and Dufour 2007) in the R language. We considered species abundances instead of presence-

21 absence data in matrix $\mathbf{L}$, the latter being the only type of data used in the original fourth-corner

22 method of Legendre et al. (1997). The correlations obtained in individual cells $\left(d_{i j}\right)$ of the $\mathbf{D}$

23 matrices were tested using 999 permutations, thereby producing $P$-values. Two permutation 
1 models were used (permutation of entire rows and entire columns), and their probabilities

2 combined, to test the null hypothesis $\left(\mathrm{H}_{0}\right)$ stating that the species traits (matrix $\mathbf{Q}$ ) are not related

3 to the environmental variables (matrix R). According to Dray and Legendre (2008), the rejection

4 of $\mathrm{H}_{0}(\mathbf{R} \leftrightarrow \mathbf{Q})$ requires two conditions (or hypotheses), (i) the rejection of the absence of a link

5 between species abundances and species traits (i.e. $\mathrm{H}_{01}: \mathbf{L} \leftrightarrow \mathbf{Q}$ ) and (ii) the rejection of the

6 absence of a link between species abundances and environmental variables (i.e. $\mathrm{H}_{02}: \mathbf{L} \leftrightarrow \mathbf{R}$ ).

7 The two hypotheses were tested using different permutation models: (i) permutation of entire

8 rows $\left(\mathrm{H}_{01}\right.$ : positions of species assemblages are independent of the environmental characteristics

9 of the sites; model type $=2)$ and (ii) permutation of entire columns $\left(\mathrm{H}_{02}:\right.$ distribution of species

10 is independent of their biological traits; model type $=4$ ). Rejection of $\mathrm{H}_{0}$ at significance level $\alpha=$

110.05 required the rejection of the two hypotheses at significance levels $\alpha_{1}=\alpha_{2}=0.2236$; in that

12 way, $\alpha=\alpha_{1} \alpha_{2}=0.05$. Only the correlations that remained significant at the 0.05 level after the $\alpha$

13 adjustment of Holm's procedure for multiple testing (Holm 1979) and $\alpha$ correction $\left(\alpha_{1} \alpha_{2}\right)$ were

14 used for ecological interpretation. According to Dray and Legendre (2008), combining results

15 from the two hypotheses seems the only way to test properly the whole link between species

16 traits and environmental variables mediated by the abundances of species. A multivariate statistic

17 (inertia or trace of matrix D), which measures the overall link between the variability of the

18 species traits and the variability of the environmental conditions, was also computed at each

19 spatial scale. That statistic, computed by the R function 'fourthcorner2' of ade4, was tested using 20 permutations.

RLQ analyses (Dolédec et al. 1996) were computed using the "rlq" function of the "ade4"

22 package. RLQ is an extension of co-inertia analysis that simultaneously finds linear combinations

23 of the variables of table $\mathbf{R}$ and linear combinations of the variables of table $\mathbf{Q}$ of maximal 
1 covariance weighted by the data in table $\mathbf{L}$ (Dray et al. 2003). It graphically summarizes and

2 represents the main co-structure in the three tables $\mathbf{R}, \mathbf{L}$ and $\mathbf{Q}$. The RLQ and fourth-corner

3 analyses were jointly used to identify the species and the environmental conditions corresponding

4 to the groups of traits. Graphical representations of the outputs of RLQ analysis (e.g., scores of

5 the species traits and environmental variables) were used for interpretation purposes. The groups

6 of species $\left(\mathrm{G}_{\mathrm{s}}\right)$, species traits $\left(\mathrm{G}_{\mathrm{t}}\right)$, and environmental variables $\left(\mathrm{G}_{\mathrm{e}}\right)$ were obtained by $K$-means

7 partitioning applied to the tables of species scores, trait scores and environmental scores of RLQ

8 analysis, respectively. $K$-means partitioning searches for the groups that minimize the total

9 within-group or "error" sum of squares (TESS), or, equivalently, the total intra-cluster variation.

10 The Calinski-Harabasz criterion, which is a pseudo- $F$ statistic as in ANOVA, was used to assess

11 the best number of groups identified by $K$-means partitioning (Calinski and Harabasz 1974,

12 Milligan and Cooper 1985).

\section{RESUlTS}

The global multivariate statistic (inertia of $\mathbf{D}$ ) of the fourth-corner analyses indicated that the overall link between the species traits and the environmental variables displayed similar patterns across spatial scales in Lake Drouin and Lake Paré (Fig. 3). Although the values from the two lakes cannot be directly compared, both lakes displayed low values at finer spatial scales (Lake Drouin: 0.48; Lake Paré: 0.68) and high values at broader scales (Lake Drouin: 2.21 at very broad scale; Lake Paré: 1.72). This suggests either that the environmental variables used in this study explained a lower proportion of the species traits variance at finer scales than at larger scales, or that other traits than feeding-oriented traits are associated with the distribution of species at the finer scales. Permutation tests conducted on the overall statistics indicated that only the very broad and broad spatial scales in Lake Drouin displayed global significant correlations 
1 between the traits and the environment (i.e. matrices $\mathbf{D}$ ). Therefore, only the trait-environment

2 relationships in Lake Drouin at these two spatial scales are further described. For simplicity, we

3 present hereafter a summary of the fourth-corner results found in matrices $\mathbf{D}$. Complete results

4 (i.e. correlation statistics in matrices $\mathbf{D}$ ) can be found in Appendix B.

The relationship between species traits and environmental conditions varied widely

6 between the very broad and broad spatial scales. When comparing the significant correlations at

7 the very-broad and broad spatial scales (matrices $\mathbf{D}$ in Appendix B), we observe that only $6 \%$ of

8 the statistically significant correlations were between the same species traits and environmental

9 conditions at the two spatial scales. Graphically, these associations can be observed in Fig. 4

10 where similar positions of the points relative to the origin in both plots indicate associations

11 between environmental variables and species traits.

\section{Groups of traits}

The $K$-means analyses, applied to RLQ scores, identified three groups of species traits in Lake Drouin at very broad (Fig. 4A) and broad spatial scales (Fig. 4B). Comparison of the composition of these groups indicates that $75 \%$ of the significant species traits were similarly grouped at the two spatial scales. The first group of traits $\left(\mathrm{G}_{\mathrm{t}} 1\right)$ included fish having a superior mouth, feeding mainly on invertebrates associated with plants or located near the water surface (surface feeders; Fig. 4A; $\Delta$ ). Two species, $N$. crysoleucas and $F$. diaphanus, were associated with this group (Table 2). The second group of traits $\left(\mathrm{G}_{\mathrm{t}} 2\right)$ included the highest number of species traits and was composed of species with a terminal mouth having mid-water (zooplankton) or benthic (zoobenthos) feeding habits (Fig. 4A; $\square$ ). This group was represented by L. gibbosus, $P$. flavescens, and S. atromaculatus at both spatial scales (Table 2). The third group of traits $\left(\mathrm{G}_{\mathrm{t}} 3\right)$ was based on the time of day at which feeding is expected to occur and, more specifically, was 
1 composed of nocturnally active species with cylindrical bodies and inferior mouth (Fig. 4A; O).

2 Fish species associated with this third group were also the same at the two scales: C. commersoni

3 and A. nebulosus (Table 2). The sums of the species abundances associated with each group of

4 traits indicated that $\mathrm{G}_{\mathrm{t}} 1, \mathrm{G}_{\mathrm{t}} 2$, and $\mathrm{G}_{\mathrm{t}} 3$ represented respectively $17.60 \%, 78.63 \%$, and $3.77 \%$ of

5 the total fish species abundances.

\section{Trait-environment relationships}

The RLQ analyses identified three groups of environmental variables at very broad (Fig. 4C) and broad spatial scales (Fig. 4D). The structure of the RLQ analyses is such that these three groups comprise environmental variables that have the highest correlations with the three groups of species traits for each of these spatial scales. At the very broad spatial scale (Fig. 4C), the first group of environmental variables $\left(\mathrm{G}_{\mathrm{e}} 1\right)$, which refers to the presence of boulders $(S 4)$ and bedrock (S5), corresponded to the environmental conditions that have the highest correlations with the species traits found in the first group of traits $\left(\mathrm{G}_{t} 1\right)$, which represents the traits associated with species defined as surface feeders. $\mathrm{G}_{\mathrm{e}} 2$ was defined by gentle slopes (Litt, Rip) and sandy bottoms $(\mathrm{Sl})$ with submerged macrophytes $(\mathrm{Subm})$. This group of environmental variables was best correlated with the species traits that characterized fish described as mid-water/ benthic feeders $\left(G_{t} 2\right)$. Finally, $G_{e} 3$ was mainly composed of deep sites $(Z)$ exposed to the action of the wind (Fetch) containing structures such as woody debris (S6), high macrophyte cover of $M$. spicatum (Cover), emergent macrophytes (Emerg), and rocks (S3). This group of sites was inhabited by nocturnally active fish species with cylindrical bodies and inferior mouth $\left(G_{t} 3\right)$. At broad spatial scale (Fig. 4D), $\mathrm{G}_{\mathrm{e}} 1$ is expected to represent the group of environmental variables best correlated with traits of surface feeders $\left(\mathrm{G}_{\mathrm{t}} 1\right)$ at that scale. This situation is consistent with the similarity between the species trait groupings obtained at the very broad and broad spatial 
1 scales. However, at the broad scale, $\mathrm{G}_{\mathrm{e}} 1$ was characterized by a gentle riparian slope (Rip) and

2 rocks as substrate (S3) and not, as found for the $\mathrm{G}_{\mathrm{e}} 1$ group at very broad scale, by boulders (S4)

3 and bedrock (S5). The $\mathrm{G}_{\mathrm{e}} 2$ group was mainly associated with the type of substrates $(S 4, S 5, S 6)$

4 and the littoral slope or variables related to the spatial organization of the sites, such as wind

5 exposition (Fetch), tributaries (Trib), the size of the sites, and the riparian use (cottages). The $\mathrm{G}_{\mathrm{e}} 3$

6 group was defined by high average depth (Z), high abundances of macrophytes (Emerg or Subm),

7 and sandy bottoms (S1; Fig. 4D).

DISCUSSION

This study intended to assess whether feeding-oriented traits determine the spatial

10 distribution of littoral fish species in lakes. The associations between the feeding-oriented traits

11 and the environmental characteristics at different spatial scales suggest that the fish community,

12 in at least one of the two lakes, was spatially structured along the vertical (strata in the water

13 column) and horizontal (habitats or environmental conditions) dimensions.

Three functional groups, two spatial scales, one significant lake

In Lake Drouin, the positive associations among the feeding-oriented traits indicated the

16 presence of three groups of species (sensu Gatz 1979b). These groups were mainly characterized

17 by the vertical distribution of the prey, the position of the mouth, and the time or period of their

18 feeding activity. The groups agreed with early studies which stated that functional groups of

19 species in lakes are likely founded on the criteria of where and how resources are used by species

20 within the water column (Schutz and Northcote 1972, Gatz 1979b). The constancy of the groups

21 of feeding traits across the spatial scales, notwithstanding the environmental variability at these

22 scales, emphasizes the idea that feeding traits are major functional drivers in structuring fish

23 communities in lakes. 
At the two broader spatial scales, the significant correlations between the species traits

2 forming the functional groups and the environmental variables highlighted the influence of

3 environmental characteristics on the organization of fish communities. Water depth and

4 macrophyte density are expected to play an important role in habitat segregation among the

5 littoral fish species (Beauchamp et al. 1994, Weaver et al. 1997, Grenouillet and Pont 2001). At

6 very broad scale in Lake Drouin, we observed that, as the environmental conditions shifted from

7 areas of low structural complexity such as sites with either boulders or bedrock as substrates to

8 shallow areas with fine sediments and high density of submersed macrophytes (i.e. high habitat

9 complexity), the functional assemblages shifted from surface feeders $\left(\mathrm{G}_{\mathrm{t}} 1\right)$ to mid-water and

10 benthic feeders $\left(\mathrm{G}_{\mathrm{t}} 2\right)$. Concurrently, the habitat of greater complexity (i.e. $\mathrm{G}_{\mathrm{t}} 2$ habitat) was also

11 the one in which we observed the highest number of functional traits (see Fig. 3) and the highest

12 relative abundance $\left(\mathrm{G}_{\mathrm{t}} 1: 17.60 \%\right.$ and $\left.\mathrm{G}_{\mathrm{t}} 2: 78.63 \%\right)$. Several studies showed that the diversity and

13 abundance of invertebrate food associated with nearshore macrophytes allow the coexistence of

14 species having multiple dietary specializations (Werner et al. 1977, Grenouillet and Pont 2001).

15 The abundance of microcrustaceans varies widely between emergent and submersed macrophytes

16 and with habitat depths (Paterson 1993), whereas insect larvae (odonata and chironomids), which

17 are the preferred prey of the mid-water and benthic groups $\left(\mathrm{G}_{\mathrm{s}} 2\right)$, are typically abundant in fine,

18 organic sediments (James et al. 1998, Weatherhead and James 2001). Direct functional

19 association, such as prey items available to fish or consumed by them, have not been surveyed

20 during our study. Yet, our interpretation is mostly based on earlier findings and theoretical

21 hypotheses on niche partitioning and habitat complexity stating that the more structurally

22 complex the habitat is, the greater diversity of functional traits it can support (Gorman and Karr

23 1978, Ross 1986, Higgins and R.E. 2008). Hori et al. (2009) recently described the relationship

24 between groups of fish appearing at the surface of, inside, and along a gradient of habitat 
1 complexity defined by the canopy-height of seagrass beds in coastal areas. They showed that fish

2 found inside the seagrass (similar to our mid-water group) preferred structurally complex habitat

3 with high seagrass biomass and high three-dimensional structure, whereas the group of surface

4 feeders preferred a less complex habitat with low seagrass biomass and high three-dimensional

5 structure.

Some environmental variables were structurally significant for different functional groups

7 at different spatial scales. This was notably the case for the fetch and the cover of M. spicatum,

8 which were both associated with $\mathrm{G}_{\mathrm{t}} 3$ at very broad spatial scale but were linked to $\mathrm{G}_{\mathrm{t}} 2$ at broad

9 scale. This result could be explained by the roles played by the environmental conditions at

10 different scales. For instance, at very broad spatial scale (i.e. large parts of the lake), exposed

11 sites with dense cover of $M$. spicatum may represent good refuges for nocturnally active species

12 during the day, whereas at broader spatial scale (i.e. habitat patches of $\sim 500 \mathrm{~m}$ ), the fetch may

13 enhance benthic productivity serving as resource areas for mid-water and benthic feeders $\left(\mathrm{G}_{\mathrm{t}} 2\right)$

14 (Mittelbach 1981, Werner et al. 1983, Tabor and Wurtsbaugh 1991, Gafny et al. 1992, Diehl

15 1993). These causal links were not properly tested in our study. We can only hypothesize on the

16 scale-dependency of some traits-environment correlations that may reflect different processes

17 operating at different scales in lakes.

Scale-dependent relationships between species biological traits and potential processes in

19 lakes have been recently observed by Irz et al. (2007) and Eros et al. (2009). These two studies

20 tested the functional convergence of three reproductive traits and four trophic traits of fish

21 species between 75 French and 168 north-east USA lakes (Irz et al. 2007) and characterized the

22 congruence between taxonomic and six trait-based fish assemblages in 125 Finnish boreal lakes

23 (Eros et al. 2009). They both found that reproduction-related traits (i.e. spawning habitat and 
1 period) were major drivers of fish assemblages, showing indeed strong intercontinental

2 convergence. Trophic-related traits, omnivores and benthivores, were to a lesser extent associated

3 with lake area (in North American and Finish lakes) and depth (in Finnish lakes). It is however,

4 difficult to overstep the results of the two aforementioned studies as they are both focusing on

5 spatial scales much broader that ours.

There were no significant relationships between the feeding-oriented traits and the environmental characteristics at the two finer spatial scales $(<10 \%$ of the total perimeter of a lake) in Lake Drouin and none at any of the studied scales in Lake Paré. Owing to the nature of

9 the data in the $\mathbf{R}, \mathbf{L}$, and $\mathbf{Q}$ matrices, the two non-significant results could be due to different

10 causes. Four hypotheses could notably explain the lack of significant relationships between the

11 fish traits (biological/physiological) and the environment conditions at a single (e.g. fine scales in

12 Lake Drouin) or multiple scales (Lake Paré). The first hypothesis refers to the low species trait

13 variability among the species present in the community to explain the lack of significant

14 relationship in lake Paré. In our study, that hypothesis can be easily refuted by comparing the

15 species richness and their related traits in each lake. The two lakes shared five over nine species

16 and the species present from one lake had similar biological traits to the species present in the

17 other lake. This suggests that the variability of the species traits in lake Paré could unlikely

18 explain the lack of traits-environment relationship in that lake. As for the lack of significant

19 relationships at finer spatial scales in lake Drouin, it could be due to the fact that the feeding-

20 oriented traits used in the study are not structurally important at finer spatial scales: species traits

21 other than feeding-oriented traits might be significant at these scales.

The second hypothesis refers to the lack of spatial variability in the species abundances.

23 This could be the case for ubiquitous species, such as L. gibbosus. Brind'Amour et al. (2005) 
1 showed, however, that the species abundances in the two lakes displayed spatial variability at

2 multiple spatial scales.

The third hypothesis refers to the random spatial distribution of the species in the studied

4 lakes. As mentioned in the previous paragraph about the second hypothesis, spatial analyses

5 conducted on the same fish communities found significant spatial patterns in both lakes,

6 indicating a non-random distribution of the fish species in the two lakes.

The fourth hypothesis is the one that may explain the lack of significant relationships in

8 lake Paré; it refers to the lack of variability in the environmental conditions. Given that the

9 anthropogenic development surrounding the two studied lakes is comparable (Drouin: 62.12\% of

10 the lake perimeter, Paré: $61.60 \%$ ), that the two lakes display similar species composition (Table

112 2), and that they also display similar geological / morphological characteristics, the only

12 difference between the two lakes lies in the variability of their environmental characteristics

13 (Table 1). The lack of significant species traits-environment relationship at any spatial scale in

14 lake Paré may hence be attributable to the lower structural diversity of the environmental

15 conditions in its littoral zone than in Lake Drouin, thus providing several habitats at multiple

16 spatial scales in that lake. The environmental complexity in Lake Drouin $(\mathrm{ECI}=4.06)$ is greater

17 than in Lake Paré $(E C I=2.38)$. This is particularly apparent for environmental variables (Table

18 1) such as fetch, depth, and woody debris (S5) which are major environmental drivers structuring

19 the littoral fish communities in lakes (Keast et al. 1978, Brosse et al. 1999a, Brosse et al. 1999b,

20 Vono and Barbosa 2001, Brind'Amour and Boisclair 2006).

21 The absence of significant species traits-environment relationship in lake Paré could also

22 be due to the greater power of the fourth-corner correlation test in the lake in which more sites

23 have been surveyed (Lake Drouin: 90 sites; Lake Paré: 60 sites). However, sensibility and power

24 analyses of the fourth-corner to the number of sampling sites have been tested using simulations 
1 in Dray and Legendre (2008). According to their results, 60 sites would not be a shortcoming of

2 the fourth-corner approach.

9 number of species.

11 Paré and lake Drouin, respectively). However, it is still comparable to the species richness found

12 in North-American lakes, where species richness ranges between 1 and 22 and the mean species

13 richness equals 6.35 (Randall et al. 1995). Dray and Legendre (2008) showed that increasing the

14 sampling size is a way to counterbalance the effects of low species richness. In our study, several

15 significant associations have been detected by the fourth-corner approach, suggesting that the

16 sampling effort is sufficient to detect significant traits-environment relationships in these two

17 lakes. However, increasing the sampling effort would probably help detect other significant

18 associations. In a more general context, this study is quite "encouraging" as we know that the

19 fourth-corner method would be more powerful in richer ecosystems, but it is still capable to

20 detect significant traits-environment relationships in a species-poor ecosystem if the sampling

21 size is sufficient.

The fourth-corner correlation statistic differs greatly from the classical bivariate Pearson's

$23 r$ as it measures the relationship between two variables (trait and environmental variable) 
1 recorded on different sampling units (species and sites); its computation thus requires to consider

2 an extra table of species abundances. Hence, the distribution of fourth-corner correlation statistics

3 is unknown, but experience shows that statistically significant values are much lower than in

4 ordinary correlation studies (Dray and Legendre 2008). Moreover, the sampling distribution

5 would probably be influenced by the number of sites or the species richness (i.e. dimension of the

6 table $\mathbf{L}$ ) considered in the analysis. Hence, correlations obtained by the fourth-corner method

7 should not be compared between studies (if the dimensions of $\mathbf{L}$ vary) or to correlation values

8 obtained in the classical bivariate case. For instance, the maximum value reached by the

9 significant correlations in our study was 0.14 . Low values could have been favored by the

10 indirect way the information about the fish species traits was gathered. Fish traits were not

11 estimated specifically for the two study lakes but were extracted from the literature, just as in the

12 fish study of the fourth-corner paper of Legendre et al. (1997). Several studies observed that,

13 beside ontogenetic shifts, fish morphology may be affected by spatial and temporal variations in

14 abiotic and biotic factors (Taylor 1999). The underlying assumption that species traits obtained

15 from the literature may adequately represent the fish traits in our study lakes may have weakened

16 our trait-environment relationships. Therefore, we suggest using direct measurements of the

17 functional traits or at least measurements gathered in the same ecosystem or geographic region

18 than the one where the species come from, whenever possible.

21 traits can be spatially structured. It also indicated that three-table statistical approaches, such as

22 the fourth-corner analysis coupled with RLQ analysis, are powerful tools to assess such

23 relationships. Approaches like the one we applied here opens up a new research direction: the 
1 study of spatially-based biological functions in lakes and in other ecosystems. To our knowledge,

2 this research field is growing in marine ecosystems (Bremner et al. 2003, Frid et al. 2008) but is

3 still in its infancy in lacustrine ecosystems. For instance, spatial patches of high functional

4 diversity or spatial distribution of essential ecological functions, such as nursery areas, have been

5 recently identified in estuaries (Islam and Tanaka 2006). Determination of biological traits

6 identified as indicators of key aspects of functioning in potential Marine Protected Areas (MPA)

7 have also been recently tested and suggested by Frid et al. (2008). Studies, such as the ones cited

8 above, are all incorporating functional aspects (assessed by species biological traits) into the

9 designation and protection of marine habitats (McLeod et al. 2009).

10 Freshwater Protected Areas (FPA, Suski and Cooke 2007) are the freshwater counterpart

11 of MPAs. As in MPAs, the success of FPAs relies notably on their spatial design, i.e. the spatial

12 arrangement and the appropriate size to optimise the exchange between productive (or functionally

13 diverse) areas (Pauly et al. 2002). An analytical approach like the one used here could help determine

14 the dominant spatial scales (i.e. geographic ranges) at which functional groups of species are varying,

15 thereby identifying habitat patches of high biological (or functional) diversity (i.e. potential FPA sizes).

\section{ACKNOWLEDGMENTS}

We thank M. Coinçon, J. Guimmond-Cataford, and C. Desroches for much appreciated

18 field and lab assistance and two referees for valuable comments. Financial support was provided

19 by scholarships from the Natural Sciences and Engineering Research Council of Canada

20 (NSERC) and Fonds québécois de la recherche sur la nature et les technologies (FQRNT) to A.

21 Brind'Amour and NSERC research funds to D. Boisclair (no. 46225) and P. Legendre (no. 7738). 
Ackerly, D. D., and W. K. Cornwell. 2007. A trait-based approach to community assembly: partitioning of species trait values into within- and among-community components. Ecology Letters 10:135-145.

Angermeier, P. L., and M. R. Winston. 1998. Local vs regional influences on local diversity in stream fish community of Virginia. Ecology 79:911-927.

Austen, D. J., P. B. Bayley, and B. W. Menzel. 1994. Importance of the guild concept to fisheries research and management. Fisheries 19:12-20.

Beauchamp, D. A., E. R. Byron, and W. A. Wurtsbaugh. 1994. Summer habitat use by littoralzone fishes in Lake Tahoe and the effects of shoreline structures. North American Journal of Fisheries Management 14:385-394.

Becker, G. C. 1983. Fishes of Wisconsin. University of Wisconsin Press, Madison.

Borcard, D., and P. Legendre. 2002. All-scale spatial analysis of ecological data by means of principal coordinates of neighbour matrices. Ecological Modelling 153:51-68.

Borcard, D., P. Legendre, C. Avois-Jacquet, and H. Tuomisto. 2004. Dissecting the spatial structure of ecological data at multiple scales. Ecology 85:1826-1832.

Bremner, J., S. I. Rogers, and C. L. J. Frid. 2003. Assessing functional diversity in marine benthic ecosystems: a comparison of approaches. Marine Ecology Progress Series 254:11-25.

Brind'Amour, A., and D. Boisclair. 2004. Comparison between two sampling methods to evaluate the structure of fish communities in the littoral zone of a Laurentian lake. Journal of Fish Biology 65:1372-1384. 
Brind'Amour et al.

1 Brind'Amour, A., and D. Boisclair. 2006. The effect of the spatial arrangement of habitats on the development of fish habitat models in the littoral zone of a Laurentian lake. Canadian Journal of Fisheries and Aquatic Sciences 63:1-17.

Brind'Amour, A., D. Boisclair, P. Legendre, and D. Borcard. 2005. Multiscale spatial distribution of a littoral fish community in relation to environmental variables. Limnology and Oceanography 50:465-479.

Brind'Amour, A., A. Rouyer, and J. Martin. 2009. Functional gains of including non-commercial epibenthic taxa in coastal beam trawl surveys: a Note. Continental Shelf Research 29:1189-1194.

Brosse, S., F. Dauba, T. Oberdorff, and S. Lek. 1999a. Influence of some topographical variables on the spatial distribution of lake fish during summer stratification. Archiv fur Hydrobiologie 145:359-371.

Brosse, S., J.-F. Guegan, J.-N. Tourenq, and S. Lek. 1999b. The use of artificial neural networks to assess fish abundance and spatial occupancy in the littoral zone of a mesotrophic lake. Ecological Modelling 120:299-311.

Calinski, T., and J. Harabasz. 1974. A Dendrite Method for Cluster Analysis. Communications in Statistics, 3:1-27.

Carlander, K. D. 1997. Handbook of Freshwater Fishery Biology. Iowa University Press, Ames, Iowa.

Díaz, S., M. Cabido, and F. Casanoves. 1998. Plant functional traits and environmental filters at a regional scale. Journal of Vegetation Science 9:113-122. 
1 Diehl, S. 1993. Effects of habitat structure on resource availability, diet and growth of

2 benthivorous perch, Perca fluviatilis. Oikos 67:404-414.

Dolédec, S., D. Chessel, C. J. F. ter Braak, and S. Champely. 1996. Matching species traits to environmental variables:a new three-table ordination method. Environmental and Ecological Statistics 3:143-166.

Dray, S., D. Chessel, and J. Thioulouse. 2003. Co-inertia analysis and the linking of ecological data tables. Ecology 84:3078-3089.

Dray, S., and A. B. Dufour. 2007. The ade4 package: implementing the duality diagram for ecologists. Journal of Statistical Software 22:1-20.

Dray, S., and P. Legendre. 2008. Testing the link between species traits and environmental characteristics: the fourth-corner problem revisited. Ecology 89:3400-3412.

Dray, S., P. Legendre, and P. R. Peres-Neto. 2006. Spatial modelling: a comprehensive framework for principal coordinate analysis of neighbour matrices. Ecological Modelling 196: $483-493$.

Eklöv, P. 1997. Effects of habitat complexity and prey abundance on the spatial and temporal distributions of perch (Perca fluviatilis) and pike (Esox lucius). Canadian Journal of Fisheries and Aquatic Sciences 54:1520-1531.

Eros, T., J. Heino, D. Schmera, and M. Rask. 2009. Characterising functional trait diversity and trait-environment relationships in fish assemblages of boreal lakes. Freshwater Biology 54:1788-1803. 
Brind'Amour et al.

1 Frid, C. L. J., O. A. L. Paramor, S. Brockington, and J. Bremner. 2008. Incorporating ecological functioning into the designation and management of marine protected areas. Hydrobiologia 606:69-79.

Gafny, S., A. Gasith, and M. Goren. 1992. Effect of water level fluctuation on shore spawning of Mirogrex terraesanctae (Steinitz), (Cyprinidae) in Lake Kinneret, Israel. Journal of Fish Biology 41:863-871.

Gatz, A. J. 1979a. Community organization in fishes as indicated by morphological features. Ecology 60:711-718.

Gatz, A. J. 1979b. Ecological morphology of freshwater stream fishes. Tulane Studies in Zoology and Botany 21:91-124.

Goldstein, R. M., and M. R. Meador. 2004. Comparisons of fish species traits from small streams to large rivers. Transactions of the American Fisheries Society 133:971-983.

Gorman, O. T., and J. R. Karr. 1978. Habitat structure and stream fish communities. Ecology 59:507-515.

Grenouillet, G., and D. Pont. 2001. Juvenile fishes in macrophyte beds: influence of food resources, habitat structure and body size. Journal of Fish Biology 59:939-959.

Harmelin-Vivien, M. L., J. G. Harmelin, C. Chauvet, C. Duval, R. Galzin, G. Lejeune, G. Barnabé, F. Blanc, R. Chevalier, J. Duclerc, and G. Lasserre. 1985. Évaluation visuelle des peuplements et populations de poissons: méthodes et problèmes. Revue d'écologie (Terre et Vie) 40:466-539.

Higgins, C. L. 2009. Spatiotemporal variation in functional and taxonomic organization of stream-fish assemblages in central Texas. Aquatic Ecology 43:1133-1141. 
Brind'Amour et al.

1 Higgins, C. L., and S. R.E. 2008. Modeling stream fish assemblages with niche apportionment models: patterns, processes, and scale dependence. Transactions of the American Fisheries Society 137:696-706.

Holm, S. 1979. A simple sequentially rejective multiple test procedure. Scandinavian Journal of Statistics 6:65-70.

Hori, M., T. Suzuki, Y. Monthum, T. Srisombat, Y. Tanaka, M. Nakaoka , and H. Mukai. 2009. High seagrass diversity and canopy-height increase associated fish diversity and abundance. Marine Biology 156:1447-1458.

Irz, P., F. Michonneau, T. Oberdorff, T. R. Whittier, N. Lamouroux, D. Mouillot, and C. Argillier. 2007. Fish community comparisons along environmental gradients in lakes of France and north-east USA. Global Ecology and Biogeography 16:350-366.

Islam, M. S., and M. Tanaka. 2006. Spatial variability in nursery functions along a temperate estuarine gradient: role of detrital versus algal trophic pathways. Canadian Journal of Fisheries and Aquatic Sciences 63:1848-1864.

James, M. R., M. Weatherhead, C. Stanger, and E. Graynoth. 1998. Macroinvertebrate distribution in the littoral zone of Lake Coleridge, South Island, New-Zeland: Effects of habitat stability, wind exposure, and macrophytes. New Zealand Journal of Marine and Freshwater Research 32:287-305.

Johnson, R. K., W. Goedkoop, and L. Sandin. 2004. Spatial scale and ecological relationships between the macroinvertebrate communities of stony habitats of streams and lakes. Freshwater Biology 49:1179-1194. 
Brind'Amour et al.

1 Keast, A., J. Harker, and D. Turnbull. 1978. Nearshore fish habitat utilization and species associations in Lake Opinicon (Ontario, Canada). Environmental Biology of Fishes 3:173-184.

Keast, A., and D. Webb. 1966. Mouth and body form relative to feeding ecology in the fish fauna of a small lake, lake Opinicon, Ontario. Journal of Fisheries Research Board of Canada 23:1845-1873.

Lamouroux, N., L. N. Poff, and P. L. Angermeier. 2002. Intercontinental convergence of stream fish community traits along geomorphic and hydraulic gradients. Ecology 83:1792-1807.

Legendre, P., R. Galzin, and M. L. Harmelin-Vivien. 1997. Relating behavior to habitat: Solutions to the fourth-corner problem. Ecology 78:547-562.

Legendre, P., and L. Legendre. 1998. Numerical Ecology. 2nd ed edition. Elsevier Science BV, Amsterdam.

Mason, N. W. H., C. Lanoiselée, D. Mouillot, P. Irz, and C. Argillier. 2007. Functional characters combined with null models reveal inconsistency in mechanisms of species turnover in lacustrine fish communities. Oecologia 153:441-452.

McGill, B. J., B. J. Enquist, E. Weiher, and M. Westoby. 2006. Rebuilding community ecology from functional traits. Trends in Ecology and Evolution 21.

McLeod, E., R. Salm, A. Green, and J. Almany. 2009. Designing marine protected area networks to address the impacts of climate change. Frontiers in Ecology and the Environment 7:362-370.

Milligan, G. W., and M. C. Cooper. 1985. An examination of procedures for determining the number of clusters in a data set. Psychometrika 50:159-179. 
Brind'Amour et al.

1 Mittelbach, G. G. 1981. Foraging efficiency and body size: a study of optimal diet and habitat use

2 by bluegills. Ecology 62:1370-1386.

Mouillot, D., S. Spatharis, S. Reizopoulou, T. Laugier, L. Sabetta, A. Basset, and T. Do Chi. 2006. Alternatives to taxonomic-based approaches to assess changes in transitional water communities. Aquatic Conservation: Marine and Freshwater Ecosystems 16:469-482.

Norton, S. F. 1995. A functional approach to ecomorphological patterns of feeding in cottid fishes. Environmental Biology of Fishes 44:61-78.

Olden, J. D., and D. A. Jackson. 2002. A comparison of statistical approaches for modelling fish species distributions. Freshwater Biology 47:1976-1995.

Paterson, M. 1993. The distribution of microcrustacea in the littoral zone of a freshwater lake. Hydrobiologia 263:173-183.

Pauly, D., V. Christensen, S. Guénette, T. J. Pitcher, U. R. Sumaila, C. J. Walters, R. Watson, and D. Zeller. 2002. Towards sustainability in world fisheries. Nature 418:689-695.

Pierce, C. L., J. B. Rasmussen, and W. C. Leggett. 1994. Littoral fish communities in southern Quebec lakes: Relationships with limnological and prey resource variables. Canadian Journal of Fisheries and Aquatic Sciences 51:1128-1138.

Piet, G. J. 1998. Ecomorphology of a size-structured tropical freshwater fish community. Environmental Biology of Fishes 51:67-86.

Poff, L. N. 1997. Landscape filters and species traits: towards mechanistic understanding and prediction in stream ecology. Journal of the North American Benthological Society 16:391-409. 
Brind'Amour et al.

1 Poizat, G., and D. Pont. 1996. Multi-scale approach to species-habitat relationships: juvenile fish

2 in a large river section. Freshwater Biology 36:611-622.

Randall, R. G., J. R. M. Kelso, and C. K. Minns. 1995. Fish production in freshwater: Are rivers more productive than lakes? Canadian Journal of Fisheries and Aquatic Sciences 52:631643.

Richards, C., L. B. Johnson, and G. E. Host. 1996. Landscape-scale influences on stream habitats and biota. Candian Journal of Fisheries and Aquatic Sciences 53:295-311.

Robb, T., and M. V. Abrahams. 2002. The influence of hypoxia on risck predation and habitat choice by the fathead minnow, Pimephales promelas. Behavioural Ecology and Sociobiology 52:25-30.

Ross, S. T. 1986. Resource partitioning in fish assemblages: A review of field studies. Copeia 2:352-388.

Santoul, F., J. Cayrou, S. Mastrorillo, and R. Céréghino. 2005. Spatial patterns of the biological traits of freshwater fish communities in south $\square$ west France. Journal of Fish Biology 66:301-314.

Schutz, D. C., and T. G. Northcote. 1972. An experimental study of feeding behavior and interaction of coastal cutthroat trout (Salmo clarki clarki) and dolly varden (Savelinus malma). Journal of the Fisheries Research Board of Canada 29:555-565.

Scott, W. B., and E. J. Crossman. 1973. Freshwater fishes of Canada. Bulletin of the Fisheries Research Board of Canada 184:966 pp.

Sokal, R. R., and F. J. Rohlf. 1995. Biometry. 3rd edition edition. W.H. Freeman \& Co., New York. 
Brind'Amour et al.

1 Southwood, T. R. E. 1977. Habitat, the templet for ecological strategies. Journal of Animal Ecology 46:337-365.

3 Southwood, T. R. E. 1988. Tactics, startegies and templets. Oikos 52:3-18.

4 Stoffels, R. J., K. R. Clarke, and G. P. Closs. 2005. Spatial scale and benthic community organisation in the littoral zones of large oligotrophic lakes: potential for cross-scale interactions. Freshwater Biology 50:1130-1145.

Suski, C. D., and S. J. Cooke. 2007. Conservation of aquatic resources through the use of freshwater protected areas: opportunities and challenges Biodiversity and Conservation 16:2015-2029.

10 Tabor, R. A., and W. A. Wurtsbaugh. 1991. Predation risk and the importance of cover for juvenile rainbow trout in lentic systems. Transactions of the American Fisheries Society 120:728-738.

13 Tall, L., A. Cattaneo, L. Cloutier, S. Dray, and P. Legendre. 2006. Resource partitioning in a grazer guild feeding on a multilayer diatom mat. Journal of the North American Benthological Society 25:800-810.

Taylor, E. B. 1999. Species pairs of north temperate freshwater fishes: Evolution, taxonomy, and conservation. Reviews in Fish Biology and Fisheries 9:299-324.

Thuiller, W., S. Lavorel, G. Midgley, S. Lavergne, and T. Rebelo. 2004. Relating plant traits and species distributions along bioclimatic gradients for 88 Leucadendron taxa. Ecology 85:1688-1699. 
Brind'Amour et al.

1 Tonn, W. M., J. J. Magnuson, M. Rask, and J. Toivonen. 1990. Intercontinental comparison of small-lake fish assemblages: the balance between local and regional processes. The American Naturalist 136:345-375.

Ultsch, G. R., S. A. Reese, M. Nie, J. D. Crim, W. H. Smith, and C. M. LeBerte. 1999. Influences of temperature and oxygen upon habitat selection by bullfrog tadpoles and three species of freshwater fishes in two Alabama strip mine ponds. Hydrobiologia 416:149-162.

Vannote, R. L., G. W. Minshall, K. W. Cummins, J. R. Sedell, and C. E. Cushing. 1980. The River Continuum Concept. Canadian Journal of Fisheries and Aquatic Sciences 37:130137.

Vono, V., and F. A. R. Barbosa. 2001. Habitats and littoral zone fish community structure of two natural lakes in southeast brazil. Environmental Biology of Fishes 61:371-379.

Weatherhead, M. A., and M. R. James. 2001. Distribution of macroinvertebrates in relation to physical and biological variables in the littoral zone of nine New Zealand lakes. Hydrobiologia 462:115-129.

Weaver, M. J., J. J. Magnuson, and M. K. Clayton. 1997. Distribution of littoral fishes in structurally complex macrophytes. Canadian Journal of Fisheries and Aquatic Sciences 54:2277-2289.

Werner, E. E., D. J. Hall, D. R. Laughlin, D. J. Wagner, L. A. Wilsmann, and F. C. Funk. 1977. Habitat partitioning in a freshwater fish community. Journal of Fisheries and Research Board of Canada 34:360-370. 
Brind'Amour et al.

1 Werner, E. E., G. G. Mittlebach, D. J. Hall, and G. F. Gilliam. 1983. Experimental tests of optimal habitat use in fish: the role of relative habitat profitability. Ecology 64:1525-

3 1539.

Zobel, M. 1997. The relative role of species pools in determining plant species richness: an alternative esplanation of species coexistence? Trends in Ecology and Evolution 12:266-

6 269.

7

8 
TABLE 1. Description of the codes, the numerical resolutions and the characteristics of the environmental variables estimated in Lake Drouin and Lake Paré. Values in columns Drouin and Paré are either percentages of occurrence or averages with their standard deviation in square bracket. * The environmental complexity index (ECI) represents the sum of the pairwise distances between the sites (formula: Appendix A).

\begin{tabular}{lllll}
\hline Environmental variable & Code & Resolution & Drouin & Paré \\
\hline Average littoral slope & Litt & Quantitative & $0.29[0.17]$ & $0.14[0.09]$ \\
Average depth & $\mathrm{Z}$ & Quantitative & $1.66[0.58]$ & $1.28[0.34]$ \\
Macrophytes & & & & \\
Average density of emergent & Emer & Quantitative & $7.49[12.70]$ & $13.95[21.03]$ \\
Average density of submersed & Subm & Quantitative & $3.43[4.62]$ & $10.99[16.45]$ \\
Bottom cover $(M$. spicatum $)$ & Cover & Percentage & $26.36[22.06]$ & $71.08[38.52]$ \\
Fetch (m) & Fetch & Quantitative & $303.63[406.63]$ & $2.964[3.62]$ \\
Distance to tributary $(\mathrm{m})$ & Trib & Quantitative & $596.76[401.94]$ & $785.86[455.89]$ \\
Surface of a sampling site $\left(\mathrm{m}^{2}\right)$ & Size & Quantitative & $215,60[52.84]$ & $207.60[80.93]$ \\
Riparian slope & Rip & Presence/absence & 24.44 & 35.00
\end{tabular}

Substrates

$\begin{array}{lcccc}\text { Sand }(<2 \mathrm{~mm}) & \text { S1 } & \text { Presence/absence } & 17.78 & 10.00 \\ \text { Rock }(60-250 \mathrm{~mm}) & \text { S2 } & \text { Presence/absence } & 41.11 & 14.44 \\ \text { Boulders }(>250 \mathrm{~mm}) & \text { S3 } & \text { Presence/absence } & 16.67 & 0.00 \\ \text { Bedrock } & \text { S4 } & \text { Presence/absence } & 1.11 & 0.00 \\ \text { Woody debris } & \text { S5 } & \text { Presence/absence } & 3.33 & 1.11\end{array}$

Riparian use

Cottage/brick wall

Presence/absence $\quad 62.22$

61.67

Forest

U2 Presence/absence

46.67

30.00 
Brind'Amour et al.

Beach

Bush

Riparian trees

Environmental complexity
U3

Presence/absence

5.56

10.00

U4

Presence/absence $\quad 26.67$

21.67

Tree

Presence/absence

24.44

43.33

index* $(\mathrm{ECI})$ 
TABLE 2. Classification of the fish species into functional groups in Lake Drouin obtained by $K$-means partitioning on the species feeding-oriented trait matrices (i.e., matrix $\mathbf{B}$ ). $\Delta: \mathrm{G}_{\mathrm{s}} 1$, $\mathrm{G}_{\mathrm{s}} 2$, O: $\mathrm{G}_{\mathrm{s}} 3$. In Lake Paré, the symbols are replaced by an $\mathrm{X}$ when a species is present in that lake.

Functional group of species $\left(\mathrm{G}_{\mathrm{s}}\right)$

Species $\quad$ Lake Drouin Lake Drouin Lake Paré

Very broad Broad

\begin{tabular}{llll}
\hline A. nebulosus & $\mathrm{O}$ & $\mathrm{O}$ & $\mathrm{X}$ \\
C. commersoni & $\mathrm{O}$ & $\mathrm{O}$ & $\mathrm{X}$ \\
C. plumbeus & Absent & Absent & $\mathrm{X}$ \\
F. diaphanous & $\Delta$ & $\Delta$ & Absent \\
L. gibbosus & $\square$ & $\square$ & $\mathrm{X}$ \\
N. crysoleucas & $\Delta$ & & $\mathrm{Absent}$ \\
P. flavescens & $\square$ & $\square$ & $\mathrm{X}$ \\
S. atromaculatus & $\square$ & $\square$ & $\mathrm{X}$
\end{tabular}

$\mathrm{G}_{\mathrm{s}} 1$ : Surface feeders ; $\mathrm{G}_{\mathrm{s}} 2$ : Mid-water feeders ; $\mathrm{G}_{\mathrm{s}} 3$ : Bottom feeders

Very broad and Broad spatial scales are defined in the analytical framework of the Methods section. 
TABLE 3. Description of the species morphological and behavioral traits used in this study.

Code numbers for the species traits are in parentheses.

\begin{tabular}{|c|c|c|c|c|c|c|c|c|c|}
\hline Species traits & & 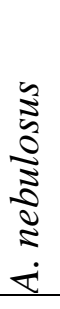 & 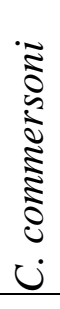 & 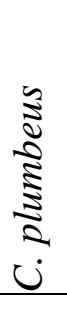 & 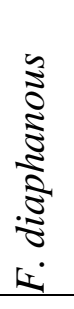 & $\begin{array}{l}3 \\
0 \\
0 \\
\vdots \\
0 \\
i \\
ن\end{array}$ & 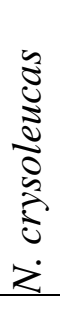 & 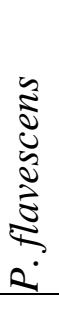 & 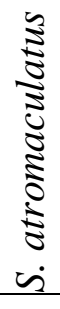 \\
\hline \multirow[t]{5}{*}{ Type of diet } & Plant (1) & 0 & 0 & 1 & 1 & 0 & 1 & 0 & 0 \\
\hline & Zoobenthos (2) & 1 & 1 & 0 & 0 & 1 & 0 & 1 & 1 \\
\hline & Zooplankton (3) & 0 & 1 & 1 & 1 & 1 & 1 & 0 & 0 \\
\hline & Insect larvae (4) & 1 & 1 & 1 & 1 & 1 & 0 & 0 & 1 \\
\hline & Fish (5) & 0 & 0 & 1 & 0 & 0 & 0 & 1 & 1 \\
\hline \multirow[t]{3}{*}{ Feeding strata } & Benthic (6) & 1 & 1 & 0 & 0 & 1 & 0 & 1 & 1 \\
\hline & Water column (7) & 0 & 0 & 1 & 1 & 1 & 0 & 1 & 0 \\
\hline & Surface (8) & 0 & 0 & 0 & 1 & 0 & 1 & 0 & 0 \\
\hline \multirow[t]{3}{*}{ Body morphology } & Fusiform (9) & 0 & 0 & 1 & 1 & 0 & 0 & 1 & 1 \\
\hline & Compressed (10) & 0 & 0 & 0 & 0 & 1 & 1 & 0 & 0 \\
\hline & Cylindrical (11) & 1 & 1 & 0 & 0 & 0 & 0 & 0 & 0 \\
\hline \multirow[t]{2}{*}{ Migration } & Daily (12) & 0 & 1 & 0 & 0 & 0 & 1 & 1 & 0 \\
\hline & Seasonal (13) & 0 & 1 & 1 & 0 & 0 & 0 & 1 & 0 \\
\hline \multirow[t]{3}{*}{ Mouth position } & Inferior (14) & 1 & 1 & 0 & 0 & 0 & 0 & 0 & 0 \\
\hline & Superior (15) & 0 & 0 & 0 & 1 & 0 & 1 & 0 & 0 \\
\hline & Terminal (16) & 0 & 0 & 1 & 0 & 1 & 0 & 1 & 1 \\
\hline
\end{tabular}


Brind'Amour et al.

Temperature

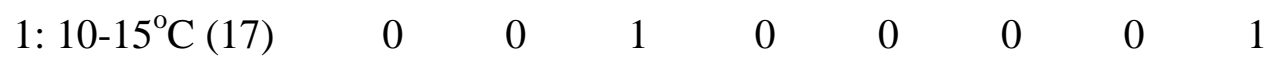

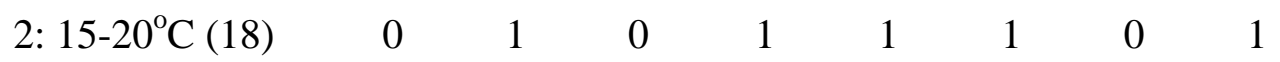

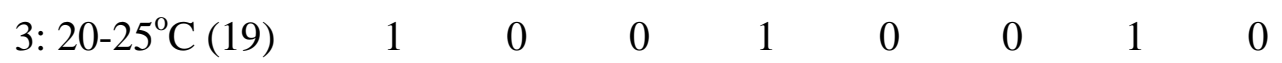

$\begin{array}{llllllllll}\text { Dissolved oxygen } & 1: 7-8 \mathrm{mg} \mathrm{L}^{-1}(20) & 0 & 1 & 1 & 0 & 1 & 1 & 0 & 1\end{array}$

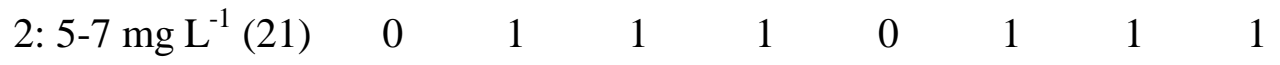

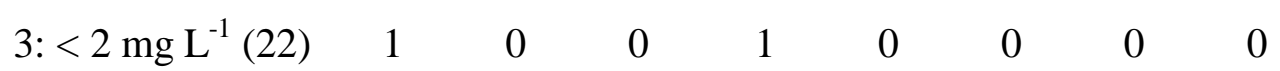

$\begin{array}{llllllllll}\text { Activity } & \text { Diurnal (23) } & 0 & 0 & 0 & 1 & 1 & 1 & 1 & 1\end{array}$

$\begin{array}{llllllllll}\text { Nocturnal (24) } & 1 & 1 & 1 & 0 & 0 & 0 & 0 & 0\end{array}$




\section{FIGURE LEGENDS}

FIG. 1. Bathymetric maps of the two study lakes on the Laurentian Shield in Québec (Canada). Depth contour values are in meters. Arrows identify inflows and outflows.

FIG. 2. Schematic flow diagram of the statistical framework used in the present study. Environmental variables were spatially modeled $(2,3)$ prior to the analyses using Principal Coordinates of Neighbour Matrices (PCNM) (constructed in 1). (4) The fourth-corner and RLQ analyses were conducted in parallel to assess the multi-scale species traits-environment relationships. The fourth-corner method was used to test statistically each combination of species traits and environmental variables and estimate the total inertia (matrix trace). RLQ analysis was used for its graphical representations of the species traits and environment ordinations (hyperspaces) which facilitated the ecological interpretation of the results.

FIG. 3. Inertia between the species traits and the environmental variables at the four spatial scales in Lake Drouin (upper panel) and Lake Paré (lower panel). ${ }^{* *} P \leq 0.001$; n.s. relationship not significant.

FIG. 4. Results of the RLQ analysis indicating the scores of species traits along the two RLQ axes for Lake Drouin (A) at very broad spatial scale and (B) at broad spatial scale and the scores of environmental variables (C) at very broad spatial scale and (D) at broad spatial scale. Positions of the points relative to the origin indicate relative contributions to RLQ axes. Ellipses delineate groups of traits $\left(\mathrm{G}_{\mathrm{t}}\right)$ and groups of environmental variables $\left(\mathrm{G}_{\mathrm{e}}\right)$ identified by $K$-means partitioning; see Methods for details. Species traits are identified by numbers defined in Table 3. To simplify the interpretation, only the traits that were tested significant using the fourth-corner analyses are displayed. See Methods section for more details. 
Fig. 1

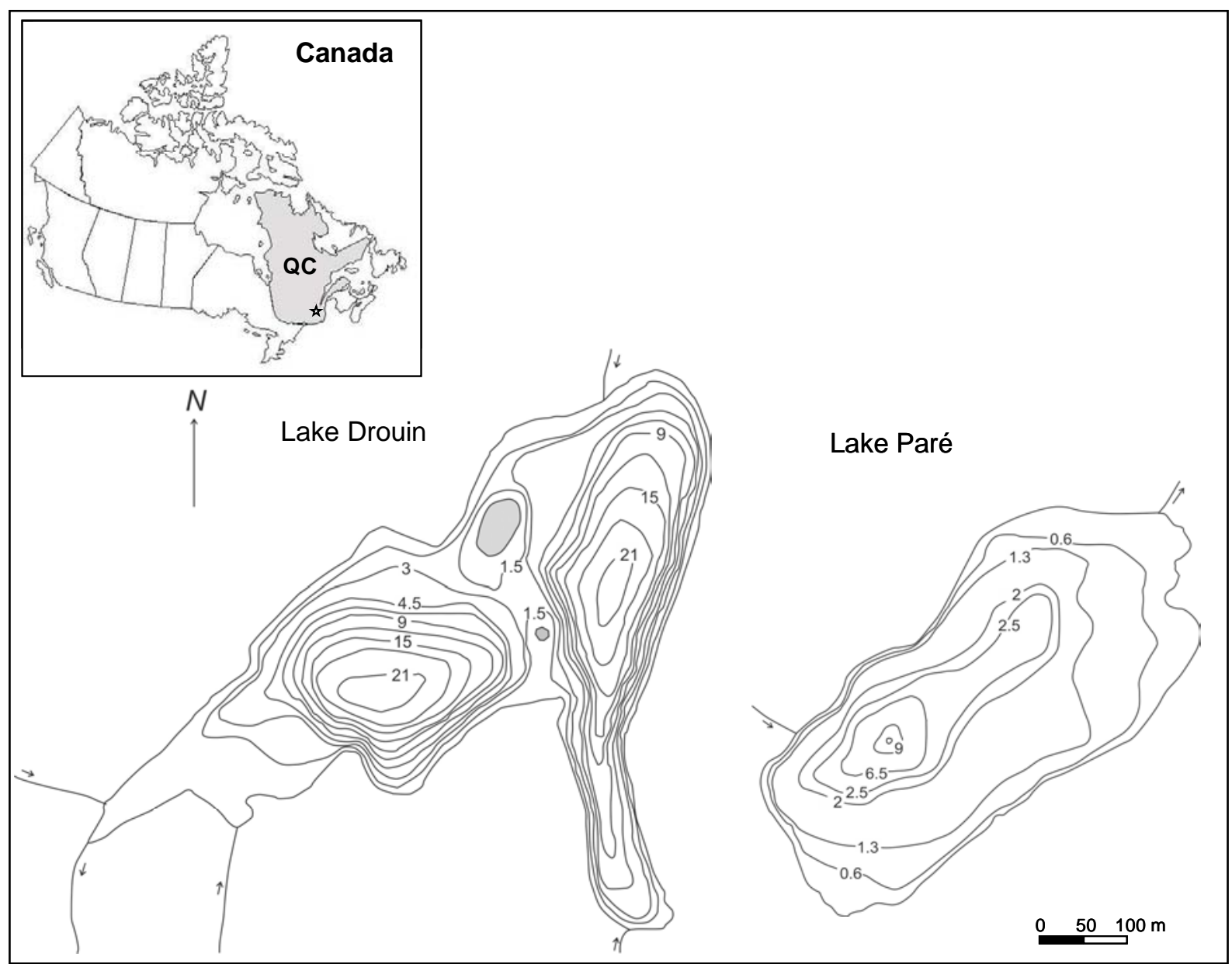


(1) Construction of spatial predictors

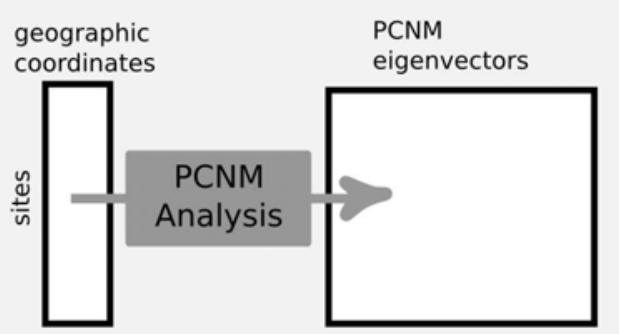

(2) Selection of spatial predictors \& Decomposition into four scales

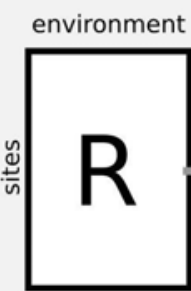

PCNM

eigenvectors

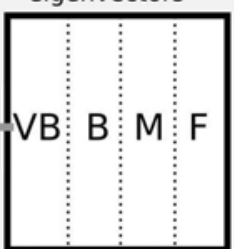

\section{Decomposition of environmental variability at multiple spatial scales}

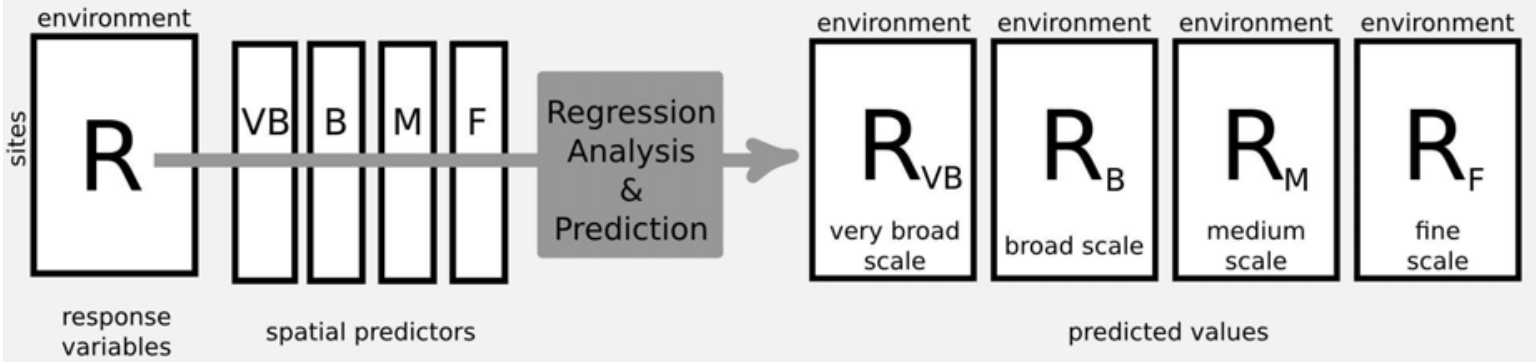

\section{(4) Analysis of species traits - environment relationships at multiple spatial scales}

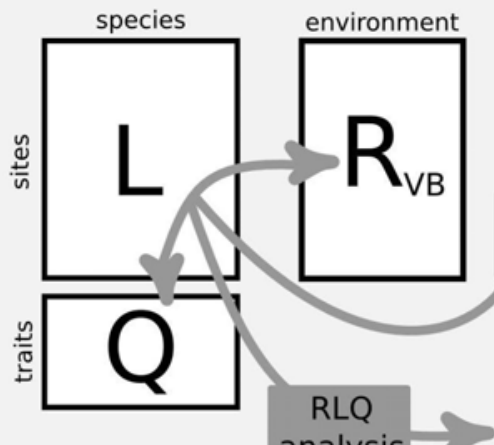

environment - Univariate tests

- Multivariate test

(inertia statistic)

Fourth-corner and RLQ analyses are repeated for each spatial scale by considering the four matrices $\mathbf{R}_{v \mathrm{v}}, \mathbf{R}_{\mathrm{s}}, \mathbf{R}_{\text {w }}$ and $\mathbf{R}$.

\section{Fourth-corner} analysis

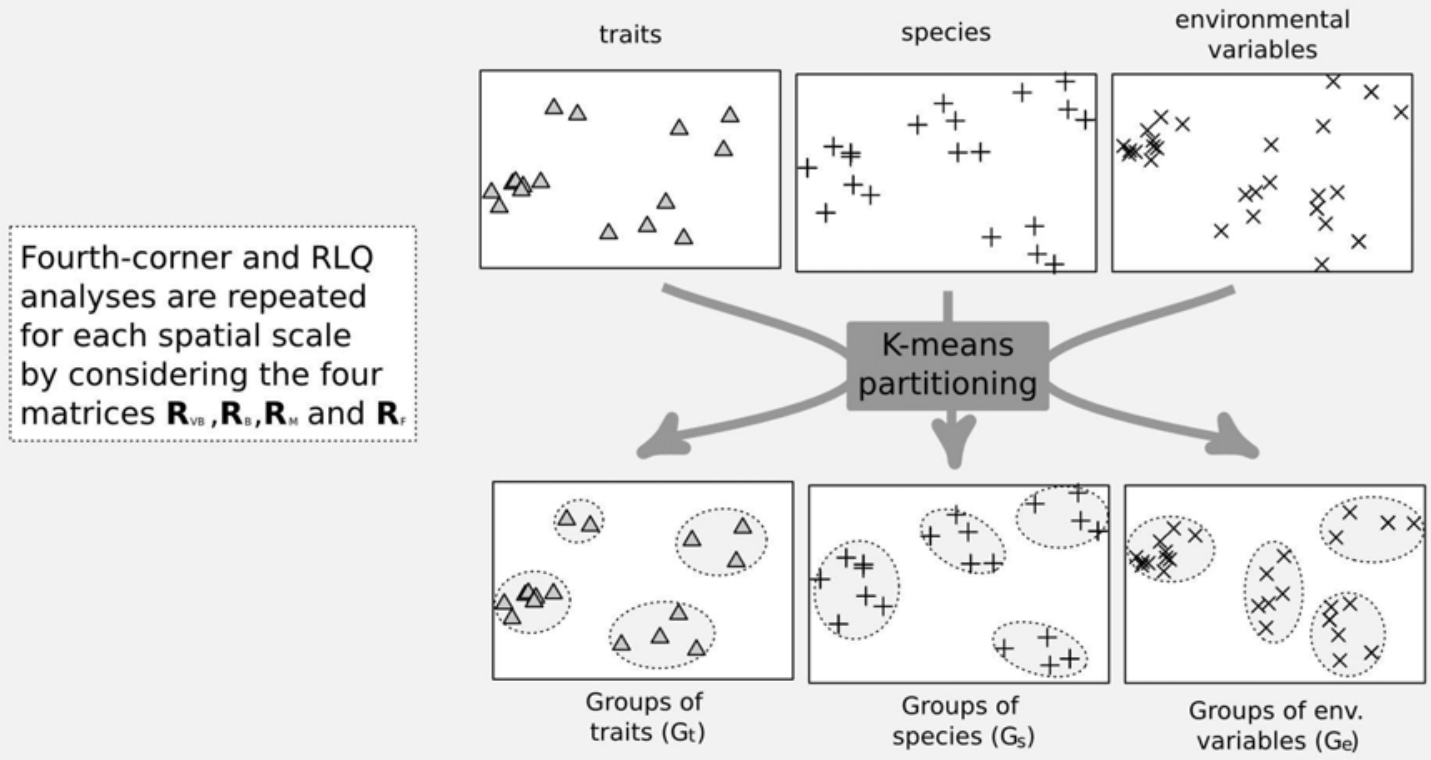




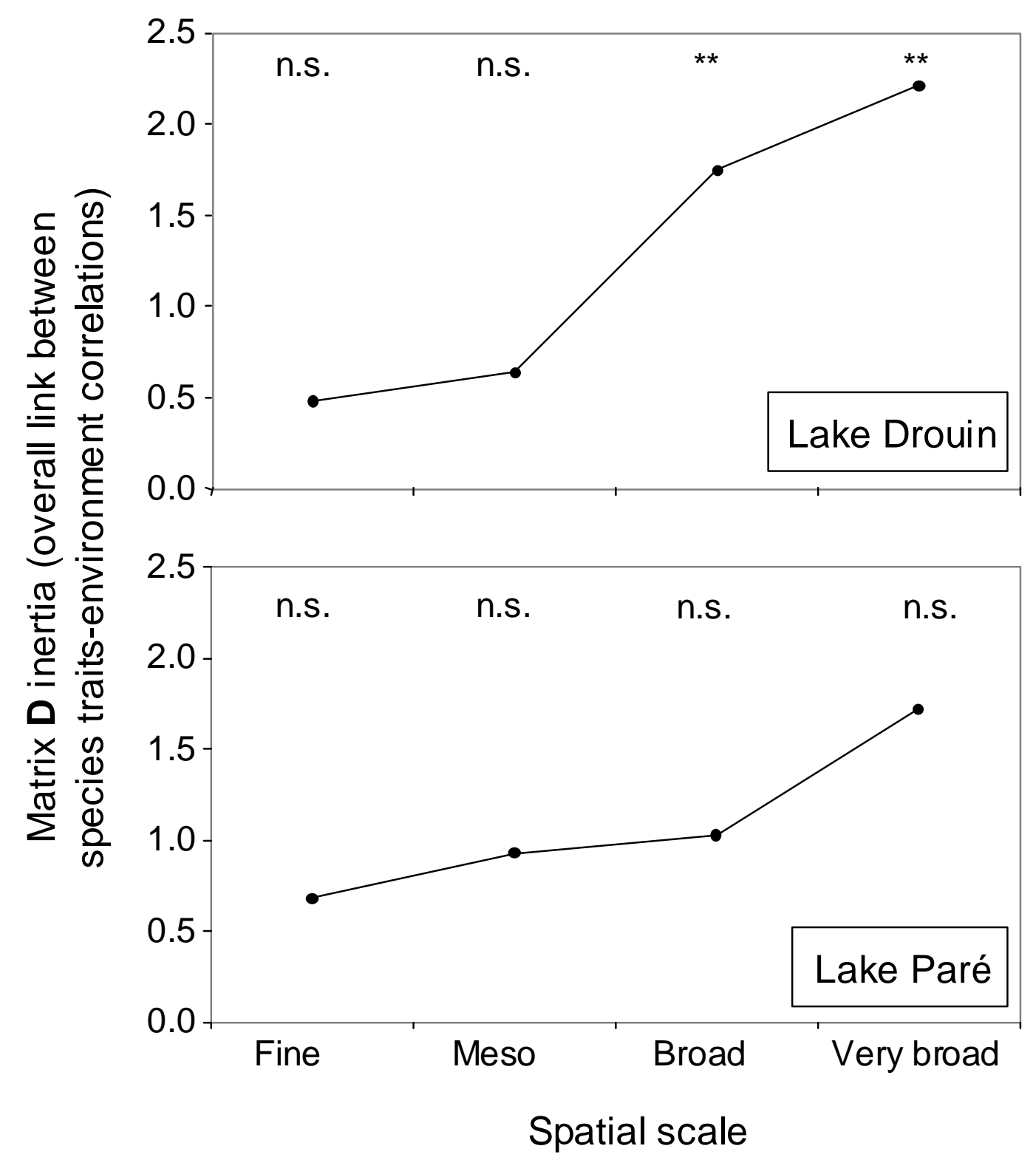



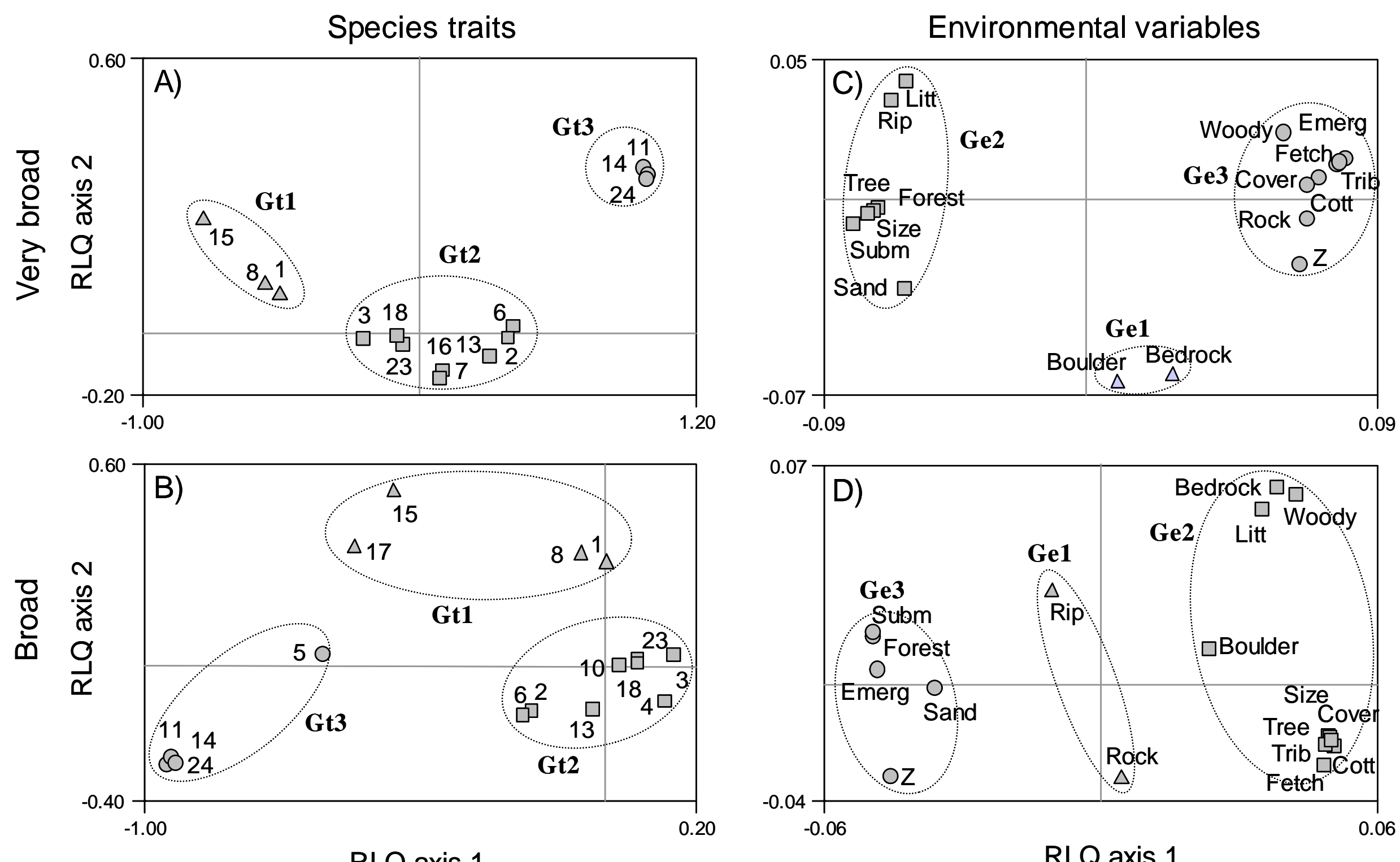

RLQ axis 1

RLQ axis 1 
Brind' Amour et al.

\section{Appendices and Supplements, p.1}

\section{APPENDIX A}

Computation of the Environmental Complexity Index (ECI)

First, we calculated a distance matrix $\left[D^{2}{ }_{h i}\right]$ among the pairs of sites using Gower's dissimilarity coefficient on the sites-environment matrix. This coefficient was chosen because it can be used with mixed variable types (quantitative, categorical, and binary) and missing values (Legendre and Legendre 1998, eq. 7.20; Podani and Schmera 2006).

From this distance matrix, we computed the index of environmental complexity (ECI) as the sum of the squared distances among the pairs of sampling sites $(i, j)$ divided by the number of sampling sites $\left(n_{\mathrm{m}}\right)$ in each lake:

$$
\mathrm{ECI}=\left[\sum_{h, i=1}^{n_{m}} D_{h i}^{2}\right] / n_{m}
$$

This equation produces a generalized form of sum-of-squares representing the total variation in the Gower dissimilarity matrix (Legendre and Legendre 1998, eq. 8.6).

\section{LITERATURE CITED}

Legendre, P., and L. Legendre. 1998. Numerical Ecology. 2nd ed edition. Elsevier Science BV, Amsterdam. Podani, J., and D. Schmera. 2006. On dendrogram-based measures of functional diversity. Oikos 115:179-185. 


\section{APPENDIX B}

\section{Ecological Application Archives xxxxxx}

\section{ASSESSMENT OF THE RELATIONSHIPS BETWEEN SPECIES TRAITS AND ENVIRONMENTAL CONDITIONS FOR LITTORAL FISH COMMUNITIES}

USING THE FOURTH-CORNER METHODAPPENDIX B: ASSESSMENT OF THE RELATIONSHIPS BETWEEN SPECIES TRAITS AND

\section{ENVIRONMENTAL CONDITIONS FOR LITTORAL FISH COMMUNITIES USING THE FOURTH-CORNER METHOD}

Table B1 Correlations from the fourth-corner analysis between the species traits (columns) and the environmental variables (rows) at very broad spatial scale in Lake Drouin. Species trait codes are found in Table 3. Each environmental variable name is followed by a line of fourthcorner correlation coefficients.

\begin{tabular}{|c|c|c|c|c|c|c|c|c|c|c|c|c|c|c|c|c|c|c|c|c|c|c|c|c|}
\hline & 1 & 2 & 3 & 4 & 5 & 6 & 7 & 8 & 9 & 10 & 11 & 12 & 13 & 14 & 15 & 16 & 17 & 18 & 19 & 20 & 21 & 22 & 23 & 24 \\
\hline & 1110 & 4 & .031 & 079 & 9 & 14 & -0.116 & .110 & 7 & 0.029 & 0.006 & 88 & .075 & -0.006 & 38 & 16 & 97 & 47 & 029 & 29 & .067 & 0.011 & .006 & 0.006 \\
\hline $\mathbf{Z}$ & & & & & & & & & & & & & & & & & & & & & & & & \\
\hline & 112 & 13 & & & & & & .112 & & & & & & & & & & & & & & & & 92 \\
\hline 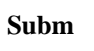 & 03 & 136 & 096 & .045 & .070 & 136 & + & & & & -0.081 & & & & & 31 & & & 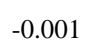 & & & & & 081 \\
\hline cove & & & & & & 129 & & & & & & & & & & & & & & & & & & 073 \\
\hline & & & & & & & & 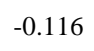 & & & & & & & & & & & & & & & & \\
\hline Tr & -0.111 & 45 & 03 & & 3 & & & 11 & 9 & $-c$ & & 22 & & & -0 & & & 0 & & & -0 & & & 93 \\
\hline Size & & & & & & & & & & & & & & & & & & & & & & & & 73 \\
\hline $\mathbf{R}$ & & 122 & & 17 & 6 & 22 & -0 & & 3 & & -0 & & & & & 66 & & & & & & & & \\
\hline $\mathbf{S}$ & & 101 & 97 & 6 & .062 & 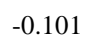 & & & & & & & & & & & & & & & & & & \\
\hline & & & & & & & & & & & & & & & & & & & & & & & & \\
\hline S4 & -0.056 & 030 & 0.047 & 3 & .011 & 030 & 88 & .056 & 39 & -0.0 & -0.067 & 5 & & -0.067 & -0 & 28 & -( & & 38 & & -0 & & & 67 \\
\hline S5 & -0.0 & 1 & & & & & & & & & & & & & & & & & & & & & & \\
\hline $\mathbf{S}$ & & & .090 & & & & & -0.0 & & -0 . & & & & & & & & & & & & & & \\
\hline S9 & & -0.120 & .080 & .048 & .060 & .120 & -0.039 & & 2 & & -0.0 & & .067 & -0. & & -0.039 & -0.032 & & -0.003 & 33 & 52 & 29 & 0.064 & -0.064 \\
\hline - & 3 & & & & & & & & & & & & & & & & & & & & & & & 0.080 \\
\hline U2 & 994 & .125 & 085 & .047 & .063 & -0.125 & -0.0 & & & & -0.0 & & 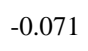 & -0. & & 0.037 & & & & & & & & -0.069 \\
\hline Tree & 095 & -0.125 & 0.086 & -0.047 & -0.064 & -0.125 & -0.036 & 0.095 & 0.000 & 0.037 & -0.070 & .031 & -0.072 & -0.070 & 0.092 & -0.036 & -0.034 & 0.079 & -0.002 & .002 & .054 & .032 & 0.070 & -0.070 \\
\hline
\end{tabular}


Table B2 Correlations from the fourth-corner analysis between the species traits (columns) and the environmental variables (rows) at broad spatial scale in Lake Drouin. Species trait codes are found in Table 3.

\begin{tabular}{|c|c|c|c|c|c|c|c|c|c|c|c|c|c|c|c|c|c|c|c|c|c|c|c|c|}
\hline & 1 & 2 & 3 & 7 & & & 7 & 8 & & 10 & & 12 & 3 & & 15 & 16 & 17 & & 19 & 20 & 21 & 22 & 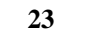 & 24 \\
\hline itt & & & & & & & & & & & & & & & & & & & & & & & & .08 \\
\hline & & & & & & & & & & & & & & & & & & & & & & & & \\
\hline & & 42 & & & & & & & & & & & & & & & & & & & & & & \\
\hline b & 12 & & & & & & & & & & & & & & & & & & & & 35 & & & \\
\hline & .011 & & & 0.097 & . & & & 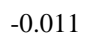 & & & & & & & & & & & & & & & & 061 \\
\hline & 021 & 021 & & & .075 & 021 & & .0 & & -0 & -0 . & 16 & & & & & & & & & & & & \\
\hline & 13 & & & & & & & & & & & & & & & & & & & & & & & -0.060 \\
\hline & 1 & 032 & & & .076 & & & .0 & & & -0.0 & & & -0. & & & & & & & & & & \\
\hline $\mathbf{R}_{\mathbf{I}}$ & 7 & 043 & 032 & 6 & 0.030 & 3 & -0 & 0.06 & & -0 & & & -0 . & & & 0 & & & & & & & & 00 \\
\hline $\mathbf{S}$ & & & & -0.04 & & & & & & & & & & & & -0. & 37 & -0.073 & & & & 13 & & 47 \\
\hline & .088 & 31 & & & 6 & & & 38 & 7 & & & 8 & & & & & -0.092 & & & & 70 & 16 & & 15 \\
\hline $\mathbf{S}$ & & & & & 3 & & & & & -0.002 & & & & & & & & & & & & & & \\
\hline & & 105 & & -0.020 & .012 & 105 & & & 3 & 0.010 & -0.09 & 00 & -0.085 & -0. & & 04 & 0. & 0.099 & -0 & & .070 & 20 & 0.097 & -0.097 \\
\hline S8 & & 14 & & 4 & .058 & 14 & -0.003 & & & & & & & & & & & & & & & & & \\
\hline S9 & .013 & .029 & 101 & & .076 & -0.029 & & 0.013 & & -0.001 & -0.060 & & -0.042 & -0.060 & & & & & 50 & & & 79 & 0.060 & -0.060 \\
\hline & .013 & -0.029 & & & .076 & -0.029 & & -0.013 & & -0.001 & -0. & & 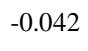 & & & & -0. & & & & & & & -0.059 \\
\hline 0 & 0.011 & 0.032 & -0.103 & -0.095 & 0.077 & 0.032 & -0.109 & 0.011 & -0.032 & -0.002 & 0.062 & 0.096 & 0.041 & 0.062 & 0.082 & -0.109 & 0.062 & -0.073 & -0.047 & 0.047 & .033 & -0.076 & -0.062 & 0.062 \\
\hline Tree & .012 & -0.031 & 0.102 & 0.096 & -0.077 & -0.031 & 0.110 & -0.012 & 0.032 & 0.001 & -0.061 & -0.098 & -0.041 & -0.061 & -0.084 & 0.110 & -0.062 & 0.073 & 0.048 & -0.048 & -0.034 & 0.077 & 0.061 & -0.061 \\
\hline
\end{tabular}


Table B3 Correlations from the fourth-corner analysis between the species traits (columns) and the environmental variables (rows) at meso

spatial scale in Lake Drouin. Species trait codes are found in Table 3.

\begin{tabular}{|c|c|c|c|c|c|c|c|c|c|c|c|c|c|c|c|c|c|c|c|c|c|c|c|c|}
\hline & 1 & 2 & 3 & 4 & 5 & 6 & 7 & 8 & 9 & 10 & 11 & 12 & 13 & 14 & 15 & 16 & 17 & 18 & 19 & 20 & 21 & 22 & 23 & 24 \\
\hline 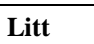 & 0.026 & 029 & 000 & -0.043 & 007 & 029 & 052 & 26 & .021 & 17 & 06 & & 4 & 0.006 & 56 & 52 & 1 & .000 & 15 & 15 & 019 & 11 & .006 & 0.006 \\
\hline $\mathbf{Z}$ & 33 & 010 & 045 & 3 & 6 & 0 & 66 & & & & & & & & & & & 23 & & & 52 & & & 80 \\
\hline & .017 & 007 & 027 & 0.012 & 4 & 7 & 12 & 17 & & & & & & & & & & & 43 & & 12 & & & 040 \\
\hline & -0.012 & .001 & 0.028 & -0.019 & 0.011 & 0.001 & -0.025 & -0.012 & 12 & -0.036 & 47 & 29 & 52 & 0.047 & -0.005 & -0.025 & -0.017 & -0.054 & .042 & -0.042 & .017 & 22 & -0.047 & .047 \\
\hline & -0.012 & 0.002 & -0.028 & -0.019 & 0.8 & 22 & -0 & -0.012 & & -0. & 0.046 & & & & 06 & 24 & -0 & 54 & 42 & & 16 & & 46 & 46 \\
\hline & -0.015 & 005 & 0.028 & -0.015 & 3 & 005 & -0.017 & -0.015 & 14 & & & & & 43 & -0.011 & 17 & & -0.053 & 42 & & 14 & & 43 & \\
\hline & 0.011 & .000 & 0.028 & 0.020 & .011 & 0 & 0.026 & 0.011 & 1 & 0 & -0.048 & 0.031 & -0.052 & -0.048 & 0.003 & 26 & 17 & 0.054 & -0.042 & 42 & .017 & 22 & 0.048 & -0.048 \\
\hline & -0.012 & 001 & .028 & -0.019 & 0 & 1 & -0.024 & -0.012 & 2 & -0.0 & 0. & 0.029 & 2 & 0. & -0.005 & -0.024 & -0. & -0.054 & 0.042 & -0. & 16 & 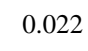 & -0 & 0. \\
\hline Rip & 0.101 & 0.079 & -0.011 & -0.053 & 0.006 & -0.079 & -0.083 & 0.101 & 0.013 & -0.016 & 0.007 & 0.050 & -0.042 & 0.007 & 0.091 & -0.083 & 0.042 & 0.027 & -0.012 & 0.012 & .076 & 15 & -0.007 & 0.007 \\
\hline * & -0.024 & 0.010 & -0.004 & -0.041 & 13 & 0.010 & -0.031 & -0.024 & 4 & 0 & 0 & 9 & 46 & 0 & 0.023 & -0.031 & -0 . & -0.029 & -0.008 & & .002 & & -0.019 & 19 \\
\hline $\mathbf{S}$ & -0.060 & .006 & 0.043 & 0.052 & .058 & .006 & 1055 & -0.060 & 03 & -0.009 & 0.0 & .053 & 0.014 & 0.0 & -0.073 & 0.055 & -0.084 & -0.027 & 0.072 & -0. & -0.051 & 0. & -0.012 & 0.6 \\
\hline S4 & -0.051 & .043 & 0.031 & 0.019 & .014 & 0.043 & 0.044 & -0.051 & -0.035 & 0.055 & -0.040 & 0.024 & -0.007 & -0.040 & -0.023 & 0.044 & -0.018 & 0.022 & -0.042 & 0.042 & -0.054 & -0.048 & 0.040 & -0.040 \\
\hline S5 & -0.050 & .003 & 0.053 & -0.008 & 9 & 3 & -0.020 & 50 & & & & & & & & -0 & & -0 . & & & -0 & & -0 . & 0. \\
\hline S8 & -0 . & .028 & 0.058 & 0.093 & -0.084 & .028 & 0.087 & -0.094 & -0.012 & & 0.013 & -0.101 & -0.011 & 0.0 & -0.110 & 87 & -0 . & -0.029 & 0.082 & -0.082 & -0.099 & & -0.013 & 0.013 \\
\hline S9 & -0.015 & .004 & -0.028 & -0.015 & 0.013 & 0.004 & -0.018 & -0.015 & 0.014 & -0.036 & 0.044 & 0.025 & 0.052 & 0.044 & -0.010 & -0.018 & -0.016 & -0.053 & 0.042 & -0.042 & 0.014 & 022 & -0.044 & 0.044 \\
\hline S & & 0.001 & 0.028 & 0. & -0.010 & & 0.030 & 0. & & & & -0.033 & -0.052 & -0.0 & 0.001 & 0.030 & & 0.054 & -0.041 & & -0.019 & -0 & 0.049 & -0.049 \\
\hline U2 & 0.011 & -0.001 & 0.028 & & -0.011 & -0.001 & & & -0.012 & & -0.048 & -0.030 & -0.051 & -0 & & & & & & & & & 48 & -0.048 \\
\hline & -0.013 & 0.002 & -0.028 & -0.018 & 0.012 & 0.002 & -0.023 & -0.013 & 0.012 & -0.036 & 0.046 & 0.028 & 0.052 & 0.046 & -0.007 & -0.023 & -0.016 & -0.054 & 0.042 & -0.042 & 0.016 & 0.022 & -0.046 & 0.046 \\
\hline
\end{tabular}


Table B4 Correlations from the fourth-corner analysis between the species traits (columns) and the environmental variables (rows) at fine spatial scale in Lake Drouin. Species trait codes are found in Table 3.

\begin{tabular}{|c|c|c|c|c|c|c|c|c|c|c|c|c|c|c|c|c|c|c|c|c|c|c|c|c|}
\hline & 1 & 2 & 3 & 4 & 5 & 6 & 7 & 8 & 9 & 10 & 11 & 12 & 13 & 14 & 15 & 6 & 17 & 18 & 19 & 20 & 21 & 22 & 23 & 24 \\
\hline$t$ & 2 & 002 & 007 & .00 & 014 & 002 & -0.0 & . 002 & 8 & 0. & .003 & 4 & 5 & 0.003 & 24 & 22 & 0.001 & .010 & .025 & 0.025 & -0.012 & -0.014 & -0.003 & 0.003 \\
\hline $\mathbf{Z}$ & 36 & 049 & 000 & 9 & 023 & 49 & & 56 & & 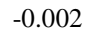 & & 35 & & & & & 5 & 015 & 16 & 016 & 25 & 28 & & .029 \\
\hline & 004 & 22 & 07 & 023 & 12 & 22 & & 4 & & & 16 & & & -0 & & & & & & & & & 46 & .046 \\
\hline nom & -0.002 & .020 & 014 & 24 & 017 & .020 & 66 & .002 & 34 & -0.05 & 0.042 & 000 & 48 & 0.042 & .037 & 006 & -0.032 & -0.014 & 062 & -0.062 & 025 & 059 & .042 & .042 \\
\hline cover & -0.002 & -0.020 & 014 & 24 & .018 & -0.020 & 66 & -0.002 & & -0.054 & 0.042 & 00 & 48 & 0.042 & 0.037 & & 2 & -0.014 & 52 & -0 & 24 & 59 & 2 & 0.042 \\
\hline & -0.001 & 21 & 010 & .023 & 15 & 21 & -0.004 & -0.001 & .036 & & -0.044 & .001 & 048 & -0.044 & & 04 & & & -0. & 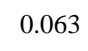 & -0.028 & 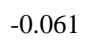 & 0.044 & -0.044 \\
\hline Trib & -0.004 & -0.020 & 016 & 0.024 & .019 & -0.020 & & -0.004 & 2 & -0.0 & 0.040 & -0.001 & 18 & 0.040 & 37 & & 35 & -0.014 & & -0. & 22 & & & \\
\hline Size & -0.002 & .020 & 13 & & 011 & -0.020 & & -0.002 & & -0.0 & & & & 0.0 & & & -0. & -0.015 & 2 & -0. & 25 & & & 0.042 \\
\hline Rip & -0.037 & 014 & 007 & 0.010 & 0.001 & 014 & 22 & -0.037 & 0.004 & -0.018 & 0.028 & 034 & 81 & 0.028 & -0.022 & 02 & -0.037 & -0.028 & 023 & -0.023 & 008 & -0.004 & -0. & 28 \\
\hline S1 & 7 & 002 & .034 & 0.009 & 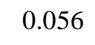 & & & & & $-0 . c$ & -0.0 & & & -0.028 & & & & & & & & & & \\
\hline & -0.003 & .015 & & & 000 & 15 & & -0.005 & & -0.0 & & & 6 & & & 99 & -0. & -0 . & & -0. & 022 & 7 & & . \\
\hline 54 & 0.002 & 0.035 & -0.003 & 1 & 0.050 & 35 & 3 & 0.002 & 0.038 & 0.004 & -0.077 & -0.035 & 000 & -0.077 & -0.041 & 83 & 0.054 & 0.050 & -0.039 & 39 & 002 & -0.048 & 0.077 & -0.077 \\
\hline 55 & 1 & .013 & 0.025 & & 051 & -0.013 & -0.025 & 0.0 & & & & -0. & 1 & & & 5 & & 0. & -0.008 & 8 & 33 & & -0 . & 25 \\
\hline S8 & & .020 & -0.019 & & & -0.020 & ses & & & & 0.0 & 1.024 & -0.040 & & & & & & & & & & & 0.002 \\
\hline S9 & -0.004 & -0.020 & 0.015 & 0.024 & -0.019 & -0.020 & 0.007 & -0.004 & 0.033 & -0.053 & 0.041 & 0.000 & 0.048 & 0.041 & -0.037 & 007 & -0.034 & -0.014 & 0.061 & -0.061 & .023 & 058 & -0.041 & 0.041 \\
\hline . & -0.002 & -0.020 & 14 & & .018 & -0.020 & & -0.002 & & -0. & & & 48 & & 37 & 6 & -0.032 & -0.014 & 0.062 & -0.062 & .024 & 59 & -0.042 & 0.042 \\
\hline 0 & 002 & 020 & & & & & & & & & & & & & & & & & & & & & & \\
\hline Tre & 02 & 020 & 13 & & & & & & & & & & & & & & & & & & 25 & & 0.042 & -0.042 \\
\hline
\end{tabular}


Table B5 Correlations from the fourth-corner analysis between the species traits (columns) and the environmental variables (rows) at very broad spatial scale in Lake Paré. Species trait codes are found in Table 3.

\begin{tabular}{|c|c|c|c|c|c|c|c|c|c|c|c|c|c|c|c|c|c|c|c|c|c|c|c|c|}
\hline & 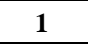 & 2 & 3 & 7 & 5 & & 7 & 8 & 9 & 10 & 1 & 2 & 13 & 14 & 15 & 16 & 17 & 18 & 19 & 20 & 21 & 22 & 3 & 4 \\
\hline & 117 & 8 & 0 & 033 & 067 & 8 & 0.051 & 089 & 7 & 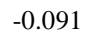 & & & & & & & 0.117 & 05 & 40 & 0.040 & 93 & -0.007 & 86 & .086 \\
\hline Z & & & & & 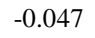 & & & & & & & & & & & & & & & & & & & \\
\hline & 44 & & & $-(1-1$ & & & & & & & & & & & & & & & & & & & & 74 \\
\hline & 57 & 104 & .008 & 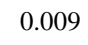 & 40 & 104 & & 288 & & & & & & & & & & -0.013 & ( & 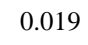 & 087 & -0.041 & & 05 \\
\hline $\operatorname{cov}$ & 557 & 04 & 88 & .009 & 40 & & & 28 & & & & & & & & & & 0.013 & & 9 & & & & 105 \\
\hline & 556 & & & 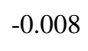 & 040 & & & . & 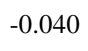 & & 0.0 & 3 & 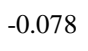 & -0. & & & & & & & & & & \\
\hline 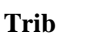 & 55 & 104 & 007 & & 040 & 04 & -0 & & 0 & -0 & & & & & & & & -0 . & -0 . & & & & & \\
\hline Size & & & & & .040 & & & 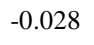 & & & -0.0 & & & -0. & & & & & & & & & & 55 \\
\hline & -0.048 & 072 & 43 & -0.040 & .010 & -0.072 & -0.080 & -0.071 & -0.010 & -0.0 & 0.0 & 7 & 3 & & 72 & & & -0.039 & 18 & -0 . & 53 & & & \\
\hline S1 & & 105 & 12 & & & & & & & & & & & & & & & & & & & & & \\
\hline & & & & & 008 & & & & & & & & & & & & & & & & & & & \\
\hline 34 & 70 & -0.092 & -0.073 & 0.070 & 0.087 & -0.092 & -0.018 & 01 & 0.087 & -0.0 & 0.018 & 2 & -0.027 & & 22 & 19 & & 0.028 & -0.059 & & 84 & & & 0.049 \\
\hline & .171 & & & 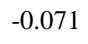 & .08 & & & 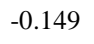 & & & & & & & & & & & & & & & & \\
\hline & & & & & 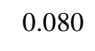 & & & & & & & & & & & & & & & & & & & \\
\hline S9 & 6 & -0.104 & -0.007 & 8 & 0.040 & -0.104 & -0.070 & 0.0 & 0.040 & -0.078 & & & 0.078 & & 4 & 2 & 56 & -0.014 & -0.019 & 19 & 086 & -0.042 & 2 & 0.102 \\
\hline 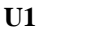 & & 1 & 0 & & 0.03 & 1 & & & & & & & & & & & & & -0 & & 72 & & & 0.079 \\
\hline $\mathbf{U} 2$ & & -0.104 & -0.001 & 0.00 & 0.040 & -0.104 & -0.069 & & & -0.077 & & & & & & & & -0.014 & -0.018 & & .085 & & & 0.102 \\
\hline Tree & -0.100 & 0.037 & 0.082 & 0.007 & -0.086 & 0.037 & 0.057 & -0.092 & -0.086 & 0.112 & -0.057 & -0.041 & -0.050 & -0.057 & -0.037 & 0.067 & -0.100 & 0.024 & -0.013 & 0.013 & -0.109 & -0.023 & 0.067 & -0.067 \\
\hline
\end{tabular}


Table B6 Correlations from the fourth-corner analysis between the species traits (columns) and the environmental variables (rows) at broad spatial scale in Lake Paré. Species trait codes are found in Table 3.

\begin{tabular}{|c|c|c|c|c|c|c|c|c|c|c|c|c|c|c|c|c|c|c|c|c|c|c|c|c|}
\hline & 1 & 2 & 3 & 4 & 5 & 6 & 7 & 8 & 9 & 10 & 11 & 12 & 13 & 14 & 15 & 16 & 17 & 18 & 19 & 20 & 21 & 22 & 23 & 24 \\
\hline & 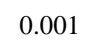 & 018 & 051 & 0.065 & 045 & 8 & 0.021 & . 004 & 5 & 029 & 1 & 5 & 0 & .021 & 18 & 6 & 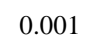 & 57 & 65 & 65 & 028 & 009 & 026 & . 026 \\
\hline Z & 00 & 020 & & & 1 & & & & & & & & & & & & & & & & & & & 08 \\
\hline & & 87 & & & & & & & & & $f$ & & & & & & & & & & & .041 & 21 & 021 \\
\hline & .015 & 042 & 037 & 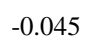 & & & & & & & & & & & & & & & & & & & & \\
\hline & 2 & 0 & & & & & & & & & & & & & & & & & & & & & & \\
\hline $\mathbf{F}$ & & & & & & & & & & & & & 3 & & & & & & & & & & & \\
\hline 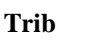 & 17 & -0.044 & 7 & & 020 & -0.044 & & & 0 & & -0.0 & 3 & 1 & & & & & & & & & & & \\
\hline Size & 10 & 8 & & & & & & & & & & & & & & & & & & & & & & 3 \\
\hline & .042 & 028 & & & 057 & 28 & & 5 & 05 & & 0 & 7 & -0.083 & -0. & 28 & & & 44 & & & 5 & & 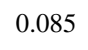 & \\
\hline 5 & 699 & 51 & 2 & 5 & .076 & 1 & -0 . & -0.087 & -0.076 & & & & 5 & & & & & & & & & & & \\
\hline S & 091 & & & 1 & & & & & & & & & & & & & & & & & & & & \\
\hline S & -0.011 & -0.003 & 40 & 36 & .034 & -0.003 & & .012 & 1034 & 55 & -0.039 & 1 & -0.050 & -0.039 & .003 & 36 & -0 . & 0.039 & -0.041 & 11 & -0.050 & -0 & .036 & 036 \\
\hline S5 & .073 & .057 & 12 & .053 & .021 & & & .059 & -0.021 & & -0.134 & 9 & 62 & -0.134 & & & & -0.028 & & & -0.095 & & & -0.146 \\
\hline S8 & & -0.005 & .051 & -0.030 & & 5 & & & & & & & & & & & & & & & & & & 0.099 \\
\hline$S$ & -0.013 & 0.040 & -0.037 & -0.044 & 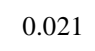 & 0.040 & -0.018 & .001 & 1 & -0 . & & & & & 0 & 3 & -0 & & & & & & 33 & 0.003 \\
\hline U1 & 0.034 & -0.056 & 0.035 & & -0.015 & -0.056 & & & -0.015 & 0.024 & -0.018 & -0.052 & -0.037 & -0.018 & 56 & -0.002 & & 0.048 & -0.067 & 67 & -0.018 & -0.037 & -0.002 & 0.002 \\
\hline U2 & 014 & 441 & .031 & 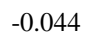 & & & 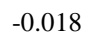 & -0.00 & & -0.030 & & & & & & & & & & & & & & 0.003 \\
\hline 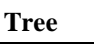 & 668 & .090 & .027 & 0.075 & 001 & 0.090 & 0.075 & .043 & .001 & 0.043 & -0.075 & -0.105 & -0.080 & -0.075 & 0.090 & .040 & 0.068 & 0.052 & -0.083 & .0.03 & -0.037 & -0.038 & 0.040 & 0.04 \\
\hline
\end{tabular}


Table B7 Correlations from the fourth-corner analysis between the species traits (columns) and the environmental variables (rows) at meso

spatial scale in Lake Paré. Species trait codes are found in Table 3.

\begin{tabular}{|c|c|c|c|c|c|c|c|c|c|c|c|c|c|c|c|c|c|c|c|c|c|c|c|c|}
\hline & 1 & 2 & 3 & 4 & 5 & 6 & 7 & 8 & 9 & 0 & 11 & 12 & 13 & 14 & 15 & 16 & 17 & 18 & 19 & 20 & 21 & 22 & 23 & 24 \\
\hline tt & 147 & 2035 & .123 & 020 & 04 & 0.035 & 2 & 162 & 0.104 & 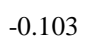 & 2 & 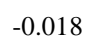 & 0.027 & 012 & 35 & .001 & 147 & 17 & -0.006 & .006 & 94 & .049 & .001 & 0.001 \\
\hline$z$ & & & & & & & & & & & & & & & & & & & & & & & & 24 \\
\hline & & 012 & & D & & & & & & & & & & & & & & & & 67 & & 07 & & \\
\hline abm & 000 & 022 & 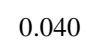 & 68 & 048 & & .039 & 07 & -0.048 & 0.021 & 9 & . & . & 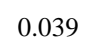 & -0.022 & -0.029 & 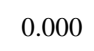 & 66 & 52 & 0.062 & -0.024 & 16 & 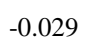 & 029 \\
\hline cover & 02 & -0.022 & 9 & 668 & & -0.0 & & & & & & & & & & 0.029 & & 56 & & 62 & 24 & 16 & 29 & 29 \\
\hline Ie & 001 & .022 & 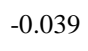 & .068 & 48 & 0 & & 8 & & .021 & 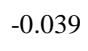 & & & 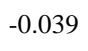 & & & 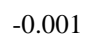 & 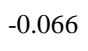 & & 0.062 & 0.024 & & & \\
\hline iib & 007 & 0.021 & .047 & 0.068 & 554 & 0.0 & .039 & 001 & -0. & 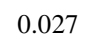 & 9 & -0 . & -0. & 9 & 21 & -0 & & 56 & & 0.062 & -0 & & & 29 \\
\hline Size & & & & & & & & & & & & & & & & -0. & & & & 2 & -( & & 9 & 29 \\
\hline & 072 & 046 & 8 & .014 & -0.068 & 6 & .011 & .060 & -0.068 & 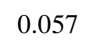 & 1 & -0.015 & -0.0 & 11 & 6 & 0. & -0 & 15 & & 00 & -0 . & 51 & 66 & 06 \\
\hline $\mathbf{S} 1$ & 32 & 3 & 7 & .052 & & & & & & & & & & & & & & & & & & & & \\
\hline & & & & & & & & & & & & & & & & & & & & 29 & & & & 977 \\
\hline S4 & 30 & 8 & .038 & .014 & 034 & 0 & .062 & 3 & 0.034 & .068 & 2 & 0 & 0. & 52 & 08 & -0.056 & 30 & -0.013 & & 16 & 66 & 09 & -0.056 & 56 \\
\hline S5 & 07 & & & $0 \Omega$ & -0.04 & & & & -0.0 & & & & -0. & & & & & & & 14 & & & & 70 \\
\hline S8 & & & & 025 & -0.061 & & & & -0.0 & & & & & & & & & & & & & & & \\
\hline 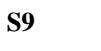 & -0.006 & -0.024 & .034 & .067 & 0.043 & -0.024 & 0.039 & -0.014 & 0.043 & -0.017 & -0.039 & & 0.035 & -0.039 & 0.024 & 0.029 & -0.006 & -0.066 & 61 & -0.061 & 0.020 & -0.018 & 29 & -0.029 \\
\hline 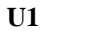 & & .022 & -0 & 068 & 19 & -0 & & 7 & & -0 & -0 & & & -0 & & & & -0 & & 62 & 25 & 16 & 30 & .030 \\
\hline 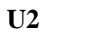 & 0.001 & -0.022 & -0.040 & -0.008 & .048 & -0.022 & 0.039 & $-0.00 /$ & 0.040 & -0.021 & -0.039 & & & -0.039 & & & -0.001 & -0.066 & & -0.062 & 0.024 & -0.016 & .030 & -0.030 \\
\hline ree & 0.071 & 0.024 & 0.118 & 0.092 & -0.123 & 0.024 & -0.028 & -0.066 & -0.123 & 0.097 & 0.028 & -0.054 & -0.059 & 0.028 & -0.024 & -0.019 & -0.071 & 0.093 & -0.089 & 0.089 & -0.098 & 0.002 & -0.019 & 0.019 \\
\hline
\end{tabular}


Table B8 Correlations from the fourth-corner analysis between the species traits (columns) and the environmental variables (rows) at fine spatial scale in Lake Paré. Species trait codes are found in Table 3.

\begin{tabular}{|c|c|c|c|c|c|c|c|c|c|c|c|c|c|c|c|c|c|c|c|c|c|c|c|c|}
\hline & 1 & 2 & 3 & 4 & 5 & 6 & 7 & 8 & 9 & 10 & 11 & 12 & 13 & 14 & 15 & 16 & 17 & 18 & 19 & 20 & 21 & 22 & 23 & 24 \\
\hline & 059 & 058 & 4 & 018 & 035 & 558 & 010 & 4 & 5 & 8 & .010 & 1 & 4 & .010 & 8 & 29 & 059 & 04 & 14 & 14 & & & 02 & 029 \\
\hline Z & 017 & 030 & 33 & & 023 & 030 & 33 & & & & & & & & & & & 07 & 17 & 17 & & & 89 & \\
\hline Em & & 883 & & & 22 & & & & & J) & & & & & & & & 11 & & & 21 & 25 & 36 & 36 \\
\hline Subm & 068 & 89 & & 045 & 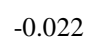 & & & & & & & & & & & & & & & & & & & \\
\hline ver & 68 & .089 & 008 & 5 & 23 & 089 & -0 & & & -0.029 & & 33 & -0.009 & & 89 & -0.044 & & 0.007 & -0.036 & 36 & 24 & 30 & $-T_{0}$ & 44 \\
\hline 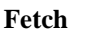 & -0.067 & 0.091 & & -0.045 & 021 & 91 & & 42 & & & -0.019 & & & -0.019 & -0 & 50 & & 06 & 35 & 35 & 25 & & 0 & -0.050 \\
\hline Iri & & 087 & & & & 7 & & & & & & 4 & 1 & & & & & 88 & 36 & 36 & & & & \\
\hline Size & 67 & -0.090 & 07 & 5 & 2 & -0.090 & -0 & & & -0 & & 2 & -0. & & & -0. & & & 6 & & & & & \\
\hline $\mathbf{R i}$ & 972 & 002 & & 0.007 & 063 & 0. & & & -0.0 & & & & -0.0 & & & & & & -0 . & & 79 & & & 36 \\
\hline & 11 & -0.077 & 065 & 0.066 & -0.056 & -0.077 & 2 & .034 & -0.056 & 0.032 & 0.032 & -0.040 & -0.019 & 2 & 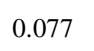 & -0.057 & 1 & 6 & -0.052 & 52 & -0.041 & 6 & & 57 \\
\hline 53 & 33 & 0.009 & 11 & 0.031 & P & 0.009 & & & & 0.030 & -0.058 & -0. & -0. & -0. & & & & & & & & & & \\
\hline & 009 & .015 & & $7+2$ & 31 & -0.015 & & & & & & & & & & & & & & & & & & \\
\hline S5 & 049 & 021 & 041 & 004 & 042 & 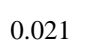 & 0.051 & 14 & -0.042 & 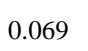 & 1 & & -0.040 & 1 & 1 & 6 & & & 9 & & & & & 66 \\
\hline 58 & 100 & 053 & .043 & -0.060 & 0.038 & $00=0$ & & -0.087 & -0.038 & 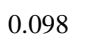 & -0.108 & -0.010 & -0.023 & -0.108 & 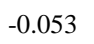 & & & & 0.035 & -0.035 & -0.082 & & & -0 . \\
\hline & -0.067 & & & 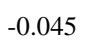 & 022 & & & 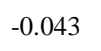 & -0.0 & & & & & & & & & & & & & & & \\
\hline U1 & 0.068 & -0.089 & -0.007 & 0.045 & 0.022 & -0.089 & -0.015 & .043 & .022 & -0.029 & 0.015 & -0.032 & -0.008 & 5 & & -0.046 & & 7 & -0.036 & 036 & 24 & 31 & -0.046 & 0.046 \\
\hline $\mathrm{U} 2$ & 067 & 0.090 & & .04 & -0.022 & & & -0. & -0.022 & 0. & -0. & & 0.1 & -0.017 & -0. & 0.048 & -0.067 & & 0.035 & -0.035 & -0.024 & -0.033 & .048 & -0.048 \\
\hline$T$ & 062 & 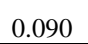 & 003 & .040 & 010 & & & .050 & .00 & 0.031 & .020 & 02 & 507 & 0.02 & .07 & $0 J$ & 0.00 & 0.0 & 03 & 0.0. & -0.024 & 0.6 & 0.058 & 0.05 \\
\hline
\end{tabular}

